FHWA/IN/JTRP-2007/9

Final Report

\begin{abstract}
APPLICABILITY OF BORMAN DECISION TREE ITS MANAGEMENT TOOL TO OTHER EXPRESSWAY SYSTEMS
\end{abstract}

\author{
Ahmed Soliman \\ Robert B. Jacko \\ Barry K. Partridge
}

June 2007 
Final Report

FHWA/IN/JTRP-2007/9

\title{
Applicability of Borman Decision Tree ITS Management Tool to Other Expressway Systems
}

\author{
By \\ Ahmed Soliman \\ Research Associate \\ School of Civil Engineering \\ Purdue University \\ Robert B. Jacko \\ Principal Investigator \\ Professor of Civil Engineering \\ Purdue University \\ Barry K. Partridge \\ Chief, Office of Research and Development \\ Indiana Department of Transportation \\ Joint Transportation Research Program \\ Project No. C-36-75Q \\ File No. 8-9-17 \\ SPR-3002 \\ Conducted in Cooperation with the \\ Indiana Department of Transportation \\ and the U.S. Department of Transportation \\ Federal Highway Administration
}

The contents of this report reflect the views of the authors who are responsible for the facts and accuracy of the data presented herein. The contents do not necessarily reflect the official views or policies of the Indiana Department of Transportation and the Federal Highway Administration. This report does not constitute a standard, specification, or regulation.

Purdue University

West Lafayette, Indiana

June 2007 
TECHNICAL REPORT STANDARD TITLE PAGE

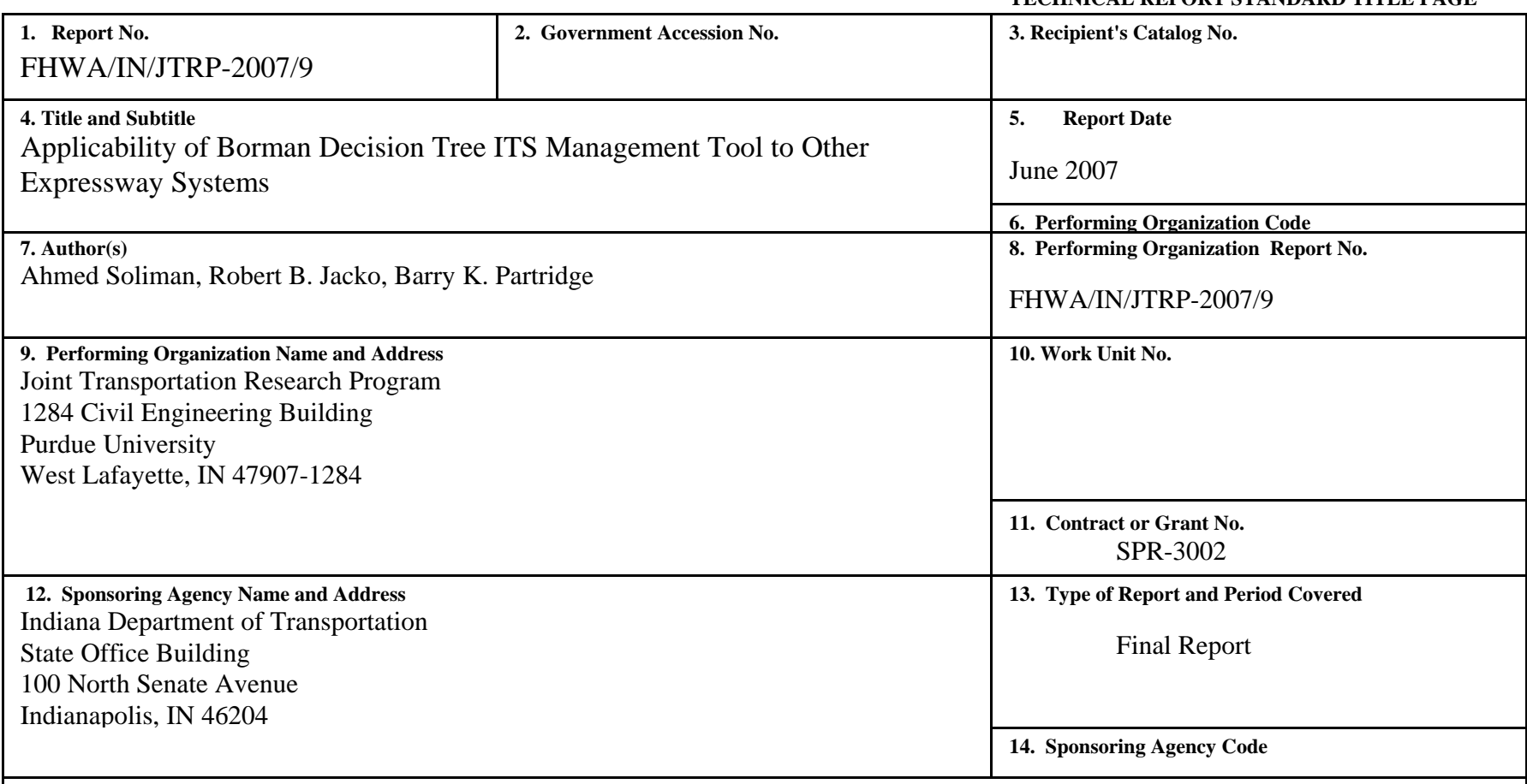

15. Supplementary Notes

Prepared in cooperation with the Indiana Department of Transportation and Federal Highway Administration.

\section{Abstract}

An empirical model called the Traffic Air Quality Model (TAQ) was developed from meteorological and PM2.5 measurements adjacent to the Borman Expressway in Northwest Indiana to estimate PM2.5 road emissions.

It concluded that on average a 74\% improvement in air quality is expected (based on reduction of mass emitted per mile [g/mi]) when the average Borman speed range is improved from $<30 \mathrm{mph}$ to $>50 \mathrm{mph}$. An additional 39\% (on average) improvement in the PM_2.5 emissions on the Borman Expressway was found when traffic flow speeds increased from 55 $\mathrm{mi} / \mathrm{h}$ to $75 \mathrm{mi} / \mathrm{h}$. The TAQ model was found to perform well when tested against measured data from I-65 at Lebanon, IN and on I-465 on the southeast side of Indianapolis . This result suggests that traffic management to reduce queues and speeds of less than $30 \mathrm{mph}$ can have a profound effect (74\% improvement) on the improvement of PM 2.5 air quality adjacent to the expressway.

17. Key Words

ITS, Intelligent, Transportation, Systems, Environmental, Air Pollution, Database, PM2.5, Fine, Particulate, Matter, Carbon, Monoxide, Borman, Expressway, Ambient Monitoring

19. Security Classif. (of this report)

Unclassified

20. Security Classif. (of this page)

Unclassified

\section{Distribution Statement}

No restrictions. This document is available to the public through the National Technical Information Service, Springfield, VA 22161
21. No. of Pages 37 


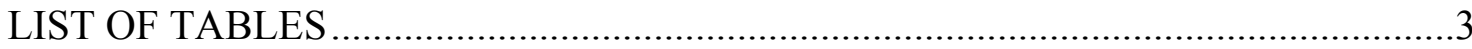

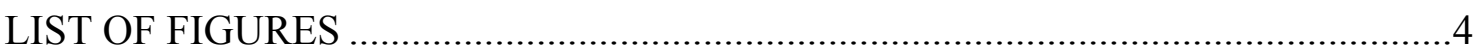

LIST OF SYMBOLS, ABBREVIATION, AND NOMENCLATURE ...........................6

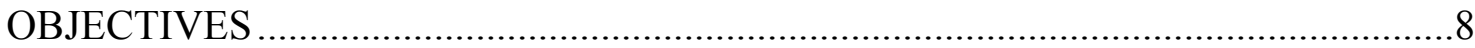

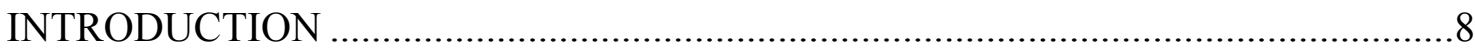

PART I: APPLICABILITY OF THE TAQ MODEL TO OTHER EXPRESSWAYS;

DATA COLLECTION AND ANALYSIS ..........................................................10

1) IL-Tollway Air Sampling Location Search ....................................................11

2) Applicability of the Borman-TAQ Model on I-65 ............................................13

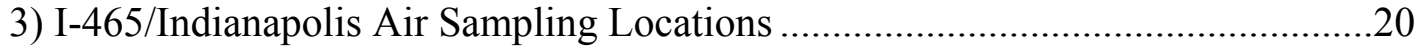

TRAFFIC PERFORMANCE MEASURES;

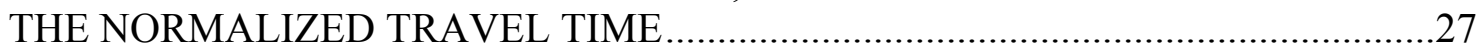

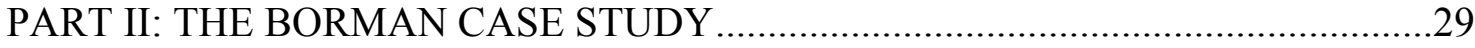

IMPLEMENTATION: THE TRAFFIC-AIR-QUALITY INDEX_..................................33

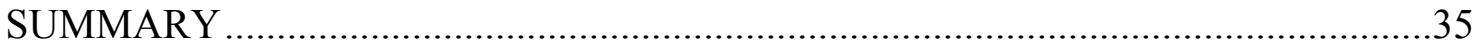

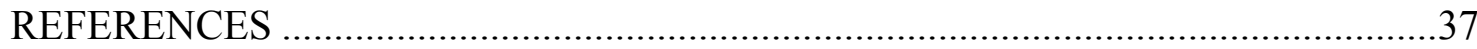




\section{LIST OF TABLES}

Table

Page

1 Summary of the Chicago location search. .......................................................12

2 Summary of the I-65 location search ........................................................21 


\section{LIST OF FIGURES}

Figure $\quad$ Page

1 The location search in the Chicago and East-Chicago area ..............................11

2 The location of the monitoring stations on I-65 near the city of Lebanon, IN ......14

3 Monitoring station "I" located on I-65 north bound, mm 138 ...........................15

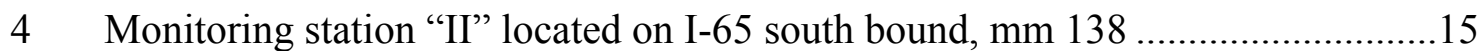

$5 \quad$ Measured and estimated PM2.5 emission factors on I-65, June 2006.................17

6 Measured and estimated PM2.5 emission factors on the Borman Expressway,

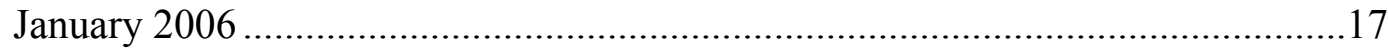

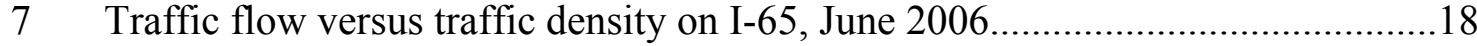

8 Traffic flow versus traffic density on the Borman Expressway,

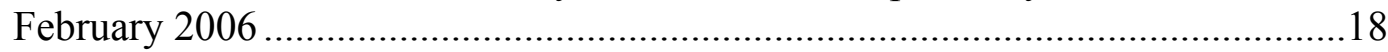

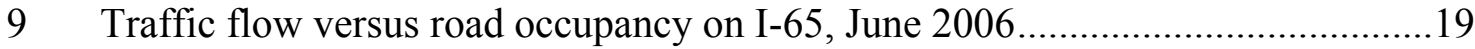

10 Traffic flow versus road occupancy on the Borman Expressway,

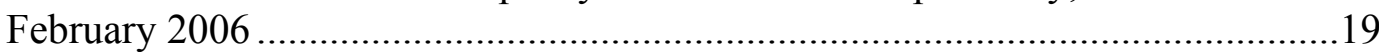

11 Map of the expressways checked in the Indianapolis area

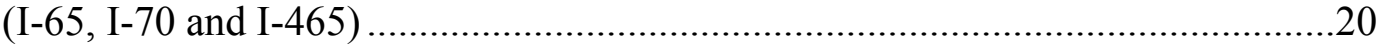

12 Best air sampling locations found south of Indianapolis .................................22

13 Locations on I-465 East bound near mm 51 south of Indianapolis. a) H\&S Parking lot, b) K\&R parking lot, and c) Carpet One Store

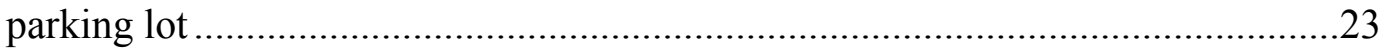

14 Locations on I-465 West bound. a) Marine Boat dealer, b) public storage ...........24

15 The RV-Location north of I-465, Indianapolis, IN ......................................25

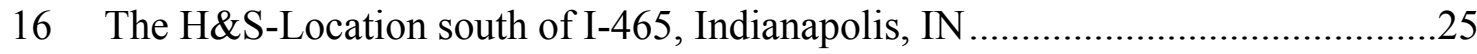

17 Measured and estimated PM2.5 emission factors on I-465, September $2006 \ldots \ldots . .26$ 
Figure

18 A schematic diagram showing the concept of the normalized travel time factor (TRN) 28

19 Normalized travel time (TRN) as a function of time during congestion and free flow for the west bound central lane of the Borman Expressway, March 15, 2005.

20 Normalized travel time factor (TRN) as a function of time for both the east and west bounds of the Borman Expressway, 3/15/2005

21 PM2.5 emission factors as a function of time for both the east and west bounds of the Borman Expressway, 3/15/2005. Curve is smoothed using a moving average function of order 10

22 Average traffic speed as a function of time for both the east and west bounds of the Borman Expressway, 3/15/2005.

Curve is smoothed using a moving average function of order 10

23 Total class-9 truck volume as a function of time for both the east and west bounds of the Borman Expressway, 3/15/2005.

Curve is smoothed using a moving average function of order 10

24 Average fleet mix as a function of time for both the east and west bounds of the Borman Expressway, 3/15/2005. Curve is smoothed using a moving average function of order 10

25 A schematic diagram of air pollution sources in urban areas and their control measures

26 A schematic diagram showing an expressway's segments conditions from an air quality point of view in a PM2.5

non-attainment area. Above quota $=\mathrm{R}$, At quota $=\mathrm{Y}$, Below quota $=\mathrm{G}$. 


\section{LIST OF SYMBOLS, ABBREVIATION, AND NOMENCLATURE}

$\begin{array}{ll}\text { Acc } & \text { Acceleration }\left[\mathrm{m} / \mathrm{s}^{2}\right] \\ \mathrm{CO} & \text { Carbon Monoxide } \\ \mathrm{E}_{1} & \text { Microscopic } \mathrm{PM}_{2.5} \text { emission factor }[\mathrm{g} / \mathrm{veh}] \\ \mathrm{E}_{2} & \text { Macroscopic } \mathrm{PM}_{2.5} \text { emission factor }[\mathrm{g} / \mathrm{mi}] \\ \mathrm{g} & \text { Gram } \\ \mathrm{h} & \text { Hour } \\ \mathrm{m} & \text { Meter } \\ \mathrm{mi} & \text { Mile } \\ \mathrm{PM}{ }_{2.5} & \text { Particulate Matter } 2.5 \text { micrometer in diameter or less } \\ \mathrm{s} & \text { Second } \\ \mathrm{S} 2 & \text { Sum of Squares } \\ \mathrm{SPD} & \text { Speed [mi/h] } \\ \text { veh } & \text { Vehicle }\end{array}$




\section{OBJECTIVES}

The objective of this project is to expand the knowledge gained from air quality and traffic measurements on the Borman Expressway to the full expanse of Indiana highways, as well as to test the applicability of the TAQ Model to the different expressways. Previous phases of the project (SPR-2926) concluded that on average a $74 \%$ improvement in air quality is expected (based on reduction of mass emitted per mile $[\mathrm{g} / \mathrm{mi}]$ ) when the average Borman speed range is improved from $<30 \mathrm{mi} / \mathrm{h}$ to $>50 \mathrm{mi} / \mathrm{h}$. Additional 39\% (on average) improvement in the $\mathrm{PM}_{2.5}$ emissions on the Borman Expressway were found when traffic flow speeds increased from $55 \mathrm{mi} / \mathrm{h}$ to $75 \mathrm{mi} / \mathrm{h}$. An empirical "Traffic-Air-Quality" (TAQ) model has been developed at the Borman site (SPR-2926) that can be used to estimate PM2.5 emissions using only traffic data input. This model can help manage the traffic conditions on Expressways to minimize air pollutant impacts utilizing the concept of a traffic-air-quality index. The analysis of the SPR-3002 project has shown the ability of the TAQ model to be used on other highways such as I-65 and I-465 in Indiana to estimate the PM2.5 levels based on traffic parameters. Conducting air quality measurements into other $\mathrm{PM}_{2.5}$-non-attainment locations in Indiana would expand the model's usefulness and potentially improve air quality along highways as the model is integrated into the ITS.

\section{INTRODUCTION}

Fine particulates, i.e., those less than 2.5 microns in diameter $\left(\mathrm{PM}_{2.5}\right)$ have been identified by the USEPA to be the most dangerous of the pollutants known to adversely affect humans. They penetrate deep into the human lung and because of their relatively large surface area to volume ratio, adsorb and absorb other toxic pollutants in the air thus delivering an enriched concentration of these toxic substances ultimately into the blood stream. Mobile sources are major contributors to air pollution in urban areas, hence, it is important to characterize and quantify the impact of traffic on air quality. Pollutants from transportation sources such as diesel and gasoline engines, brake dust and tire/road dust are exacerbated during unstable conditions on expressways due to acceleration, deceleration, braking and lane changing. 
Several techniques have been used to empirically estimate the emission factors for both Light-Duty-Vehicles (LDV) and Heavy-Duty-Vehicles (HDV). One of such techniques is the dynamometer-laboratory-tests which are performed by measuring emissions directly from individual vehicles under different engine loads and temperatures as well as for the different fuel mixes ${ }^{[1,2,3]}$. However, since individual vehicles may have diverse emission profiles, they cannot be fully representative of the whole fleet, hence, such techniques do not fully simulate the "real-world" driving condition and the emission factors may not completely reflect real emissions on the road. To obtain a more comprehensive view of real-world emission factors, a study of emission factors for the whole fleet under "real" driving conditions needed to be performed. Such studies are normally performed in urban areas and emission factors can be obtained in three ways: 1) tunnel measurements ${ }^{[4]}, 2$ ) inverse-dispersion modeling of streets ${ }^{[5]}$ and street canyons ${ }^{[6]}$, and 3) mass conservation-box model of open road measurements ${ }^{[7]}$. Other means of estimating the real-world emission factors include direct measurements of the tail-pipe emissions either by using remote-sensing techniques such as open path Fourier Transform Infrared Spectroscopy (FTIR) ${ }^{[8,9]}$, or using on-board instruments to measure emissions $^{[10]}$.

Estimation of emission factors using the mass conservation-box model of openroad-measurements method faces the problem of estimating the dimensions of the mixing-box volume. Unlike tunnel studies, where the pollutant mixing volume may be estimated to be the same turbulent air volume of the tunnel caused by the vehicle movement (also known as the piston-effect ${ }^{[11]}$ ); open-street empirical emission factor estimation encounters the difficulty of estimating the turbulent mixing volume of the pollutants on the side of the road. The dimensions of the mixing-box volume can be calculated using: $\mathrm{V}=\mathrm{L} \times \mathrm{A}$, where " $\mathrm{L}$ " is the length of the exposed portion of the road, and "A" is the turbulent area behind the moving trucks. " $\mathrm{A}$ " consists of "W", the mixing boxwidth and " $\mathrm{H}$ " which is the turbulent-mixing-box height. In some analysis, "W" can be assumed to be the width of the road, and " $\mathrm{H}$ " can be determined by measuring the pollutant concentration of as a function of height near the road ${ }^{[7]}$. However, trafficinduced turbulence plays a major role in the dispersion of pollutants near highways and hence affecting the dimensions of "A". Several studies have been conducted to model the 
dispersion of different pollutants in the wake of vehicles ${ }^{[12,13]}$. Other research focused on the dispersion that is due to the turbulence adjacent to a major road ${ }^{[14,15]}$. Wind-tunnel experiments have also been conducted to model the dispersion of the vehicular-emitted pollutants for cross winds to the road ${ }^{[16]}$.

The Borman Expressway project in northwest Indiana characterized the effect of traffic along the expressway on the local air quality adjacent to the road. Such characterization was done by analytically developing the Traffic Air Quality Model (TAQ-Model) to estimate the $\mathrm{PM}_{2.5}$ emission factors (pollutant-mass per road-length, $[\mathrm{g} / \mathrm{km}]$ ) for the expressway under different driving conditions. $\mathrm{PM}_{2.5}$-concentration measurements, meteorological and traffic measurements as well wind tunnel analysis have been conducted in this research to estimate such emission factors and used it to develop the TAQ Model for the $\mathrm{PM}_{2.5}$ emissions. Detailed information on the experimental setup and the TAQ-Model development are found in Soliman et. al, $2006^{[17}$, 18].

This report is divided into 2 parts, the first part (PART I) discusses the location search at the different highways for traffic and air quality measurements. Part I also shows the applicability of the TAQ Model to the Indiana highways. The second part (PART II) introduces different case studies where the TAQ Model is used to quantify the impact of expressway's traffic conditions on the fine particulate emissions. The concept of "normalized travel time" is introduced to determine the traffic conditions on the expressway ranging from free flow to slow moving traffic. The TAQ model is then used to estimate the $\mathrm{PM}_{2.5}$ emissions for each of the cases. Finally, the concept of a Traffic Air Quality Index is proposed as a mean of controlling fine particulate traffic-emissions in non-attainment areas.

\section{PART I: APPLICABILITY OF THE TAQ MODEL TO OTHER EXPRESSWAYS; DATA COLLECTION AND ANALYSIS}

The measurements location search started at the Indiana/Illinois border into the Chicago area (PM2.5 non-attainment area), then proceeded to the I-65 in Indiana as well I-465 south of Indianapolis. 


\section{1) IL-Tollway Air Sampling Location Search:}

A location search for the air-pollution and traffic-data sampling trucks was conducted on Saturday July 1, 2006 around the city of Chicago, IL covering 4 major links located between locations 1 through 5 on the map. The search started at the I-90 exit on I65 in Indiana (location 1 on the map) and covered the tollway I-90 to the I-290 exit on downtown Chicago (location 2 on the map). The search continued covering I-290, Tollway I-294 and I-294/80, figure 1.

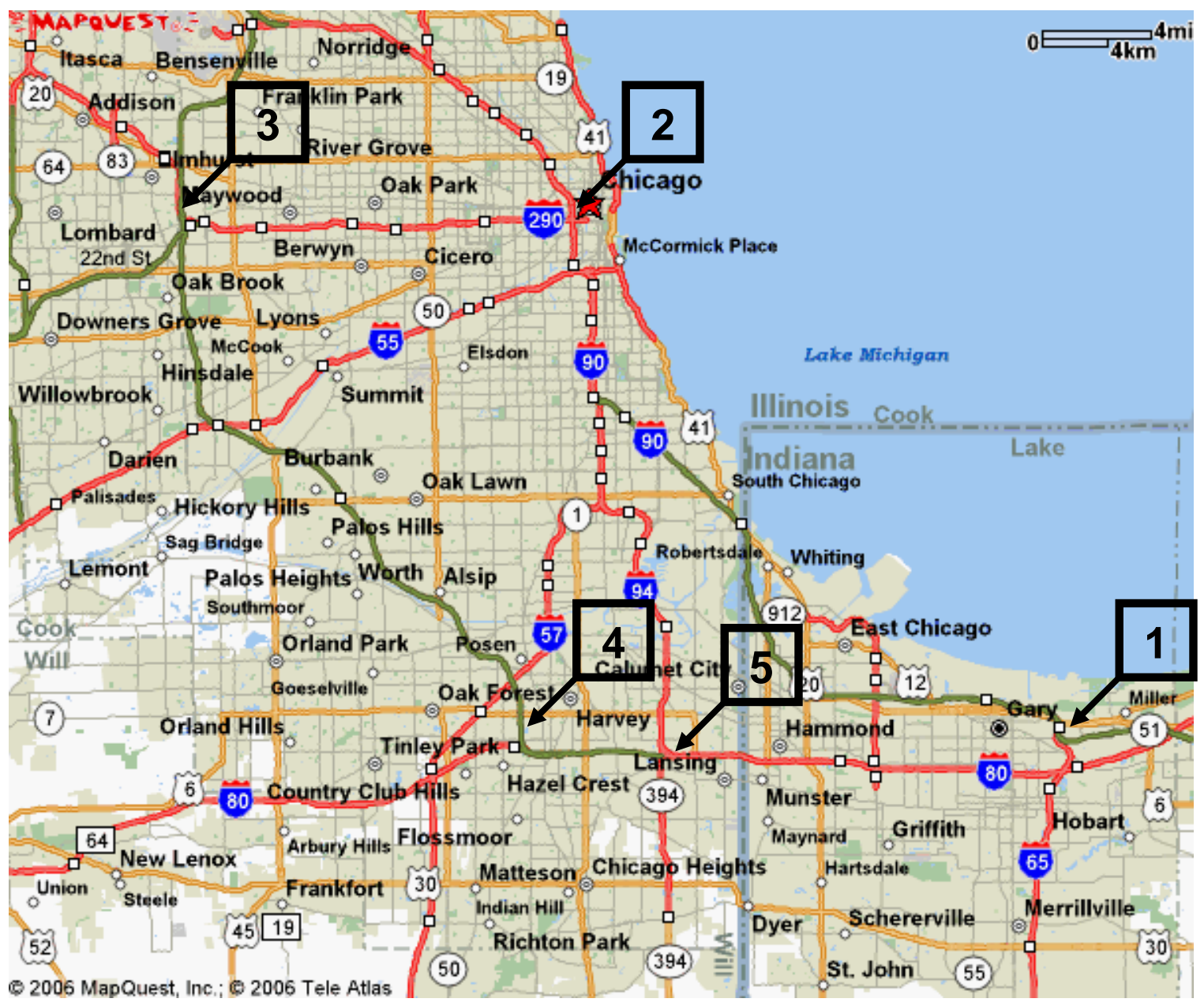

Figure 1. The location search in the Chicago and East-Chicago are.

The sampling site location criteria are: 1) the site has to be near the expressway, 150 feet or less. 2) The expressway has to carry truck volume enough to affect the surrounding air quality. 3) The location has to be away from constructions, a previous 
study (SPR-2926) has found that road construction increases the $\mathrm{PM}_{2.5}$ deposition rate by three folds which would bias the collected air pollution concentration data affecting the TAQ model analysis. 4) The site should have easy access to electric power, for example near businesses, houses or traffic boxes. 5) The expressway should have significant traffic congestions along the expressway near the site location, such possibility increases by being located near major cities or being located upstream from a major road construction site.

The following table, table 1, summarizes the main observations of potential site locations on the links marked on the map above. Note; none of the sites has met all the criteria discussed above:

Table 1. Summary of the Chicago location search.

\begin{tabular}{|c|c|c|}
\hline Expressway & Link Covered & Notes \\
\hline $\mathrm{I}-90$ & $\begin{array}{c}\text { Link between } 1 \text { and } \\
2 \text { on the map }\end{array}$ & $\begin{array}{l}\text { Heavy traffic congestions, but low truck count. } \\
\text { No apparent good location for the air sampling } \\
\text { vans. The Skyway Oasis ( } \mathrm{mm} 2 \text { ) might be a good } \\
\text { location; however, there is not enough area for } \\
\text { parking the vans. }\end{array}$ \\
\hline $\mathrm{I}-290$ & $\begin{array}{c}\text { Link between } 2 \text { and } \\
3 \text { on the map }\end{array}$ & $\begin{array}{l}\text { Heavy traffic congestions, but low truck count. } \\
\text { No apparent good location for the air sampling } \\
\text { vans. }\end{array}$ \\
\hline $\mathrm{I}-294$ & $\begin{array}{c}\text { Link between } 3 \text { and } \\
4 \text { on the map }\end{array}$ & $\begin{array}{l}\text { The Hinsdale Oasis }{ }^{*} \text { at mm } 26 \text { is a good location. } \\
4 \text { lane highway each way. No construction, free } \\
\text { flow traffic, and low truck count. The oasis is } \\
\text { located up hill from the road level. }\end{array}$ \\
\hline $\mathrm{I}-294$ & $\begin{array}{c}\text { Link between } 3 \text { and } \\
4 \text { on the map }\end{array}$ & $\begin{array}{l}\text { At } \mathrm{mm} 18 \text {, businesses on both sides of the road, } \\
\text { located around } 100 \text { feet away from expressway } \\
\text { but surrounded by trees (trees act as sinks for } \\
\mathrm{PM}_{2.5} \text { ). } 3 \text { lanes each way, downstream from } \\
\text { tollbooth, heavy congestions, but low truck } \\
\text { count. }\end{array}$ \\
\hline I-294 & Link between 3 and & 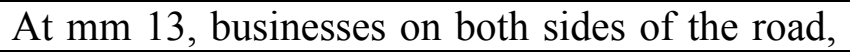 \\
\hline
\end{tabular}

* Oases are buildings built above and across the highways, with parking lots uphill from the road. Although they have good locations and power supply, however, these buildings may block winds or may cause "reflections" that may bias the pollution concentration data. 


\begin{tabular}{|c|l|l|}
\hline & 4 on the map & $\begin{array}{l}\text { located around 100 feet away from expressway, } \\
\text { a truck dealer on the south bound and a store } \\
\text { parking lot on the north bound. The location is } \\
\text { near Cicero Ave, 3 lanes each way. The } \\
\text { expressway is little elevated above the } \\
\text { businesses parking lots. Low truck count. }\end{array}$ \\
\hline I-294/I-80 & $\begin{array}{l}\text { Load construction, significant traffic } \\
\text { Link between 4 and } \\
5 \text { on the map } \\
\text { way (location of lanes changes according to the } \\
\text { road construction. Lincoln Oasis }{ }^{*} \text { (mm 1) maybe } \\
\text { a good location for parking the monitoring } \\
\text { stations. }\end{array}$ \\
\hline I-94/I-80 & $\begin{array}{c}\text { Link between 5 and } \\
1 \text { on the map }\end{array}$ & $\begin{array}{l}\text { Analysis has already been performed in SPR- } \\
2926 .\end{array}$ \\
\hline
\end{tabular}

No sites were chosen at the Illinois locations due to the difficulties mentioned in the above table.

\section{2) Applicability of the Borman-TAQ Model on I-65:}

Site Location: Two traffic-air quality mobile monitoring stations were placed on the I-65 north and south bounds at the mile marker 138 on both bounds for the period of May 31, 2006 to June 12, 2006. The monitoring stations were both located around 25 feet ( 7.6 meters) away from the expressway. Figure 2 shows a map of the monitoring locations on I-65 near the city of Lebanon. 


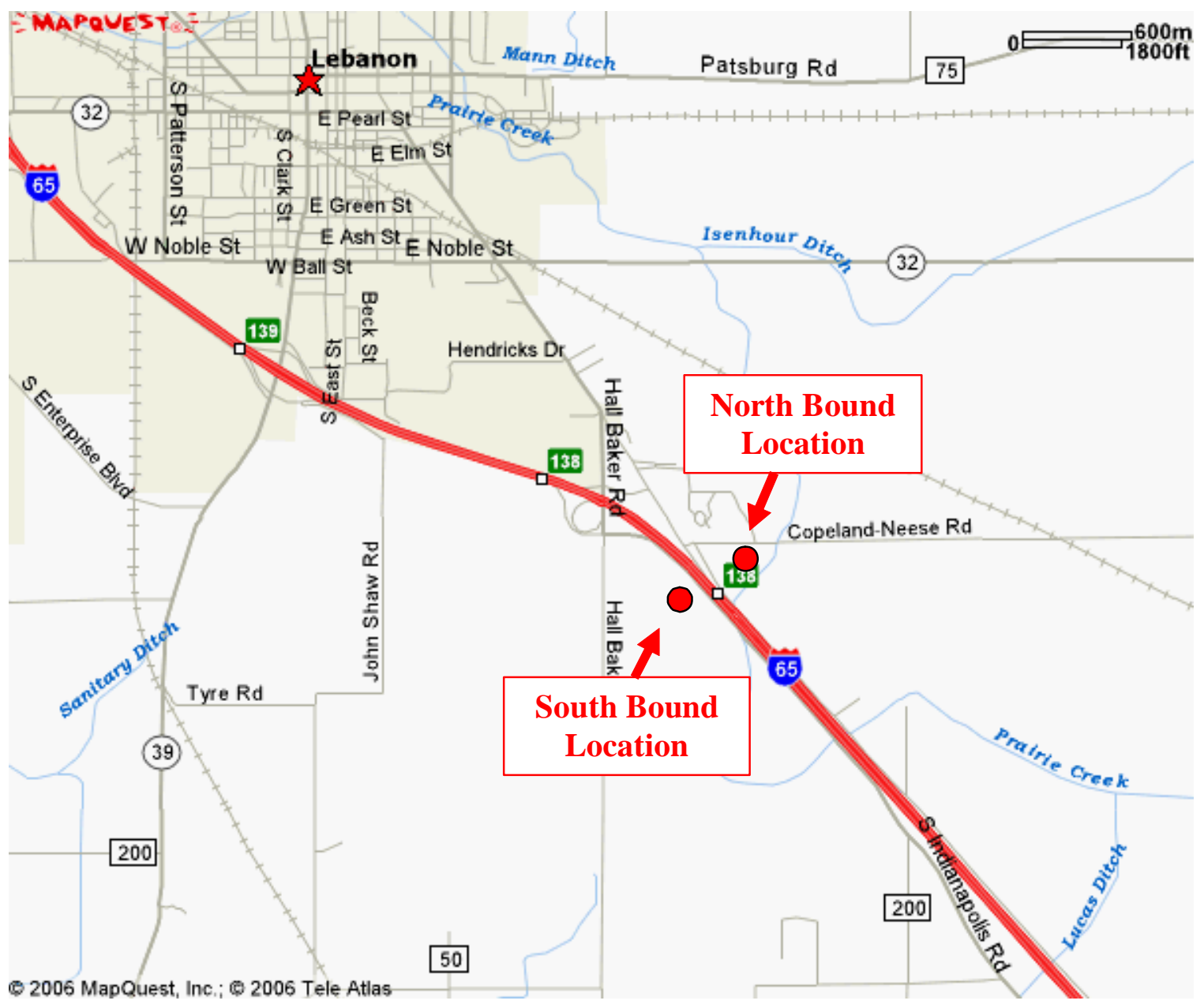

Figure 2. The location of the monitoring stations on I-65 near the city of Lebanon, IN.

Figures 3 and 4 show the mobile monitoring stations located on the north and south bounds of I-65, stations I and II respectively. Station "I", collects north-bound traffic, $\mathrm{PM}_{2.5}$ concentration, wind speed, wind direction and temperature. Station "II" collects south-bound traffic, $\mathrm{PM}_{2.5}$ concentration, and temperature. 


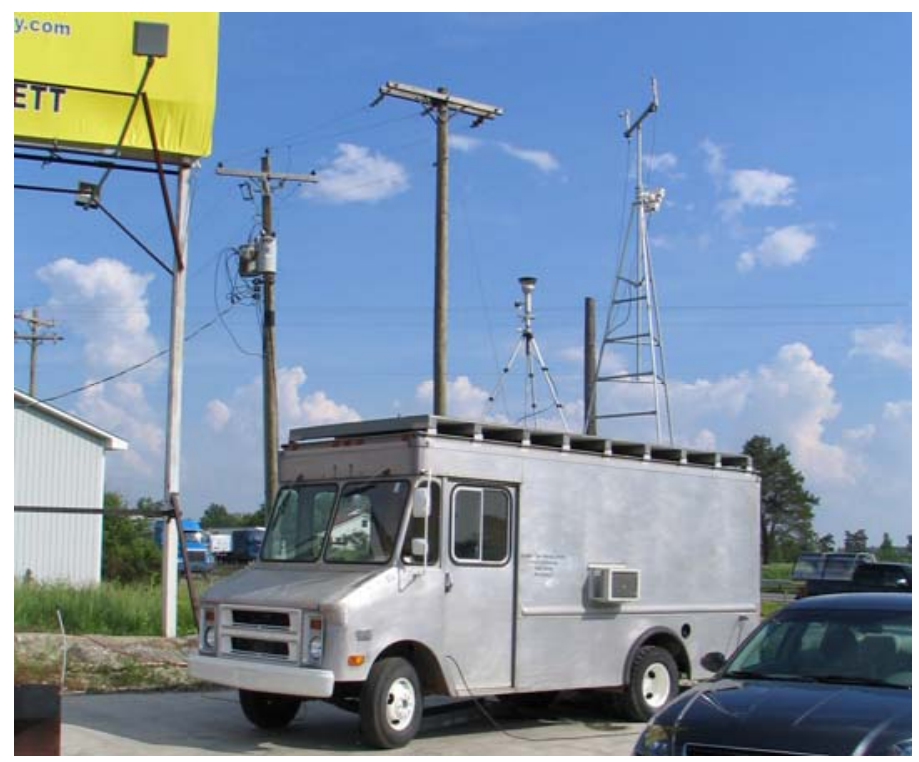

Figure 3. Monitoring station "I" located on I-65 north bound, mm 138.

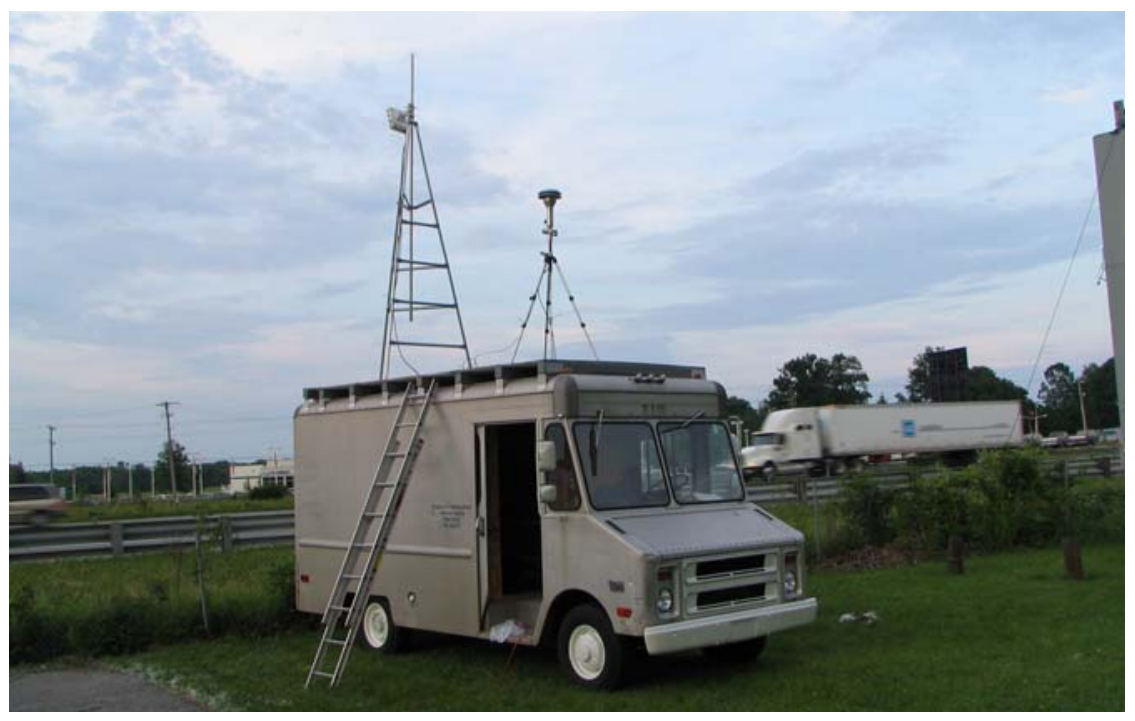

Figure 4. Monitoring station “II” located on I-65 south bound, mm 138.

Measured and Estimated Data Analysis for I-65: $\mathrm{PM}_{2.5}$ emission factors [g/mi] of I-65 have been calculated from measured data as well as estimated using the Borman Traffic-Air-Quality Model (TAQ-Model), then the results were compared to test the applicability of the TAQ model to the different highways in Midwest states. 
The measured $\mathrm{PM}_{2.5}$ emission factors " $\mathrm{E}$ " $[\mathrm{g} / \mathrm{mi}]$ were calculated using equation 1:

$$
E=\frac{C \times U}{Q_{T}} \times V^{2 / 3} \times K_{T}
$$

Where, "C" is the $\mathrm{PM}_{2.5}$ concentration $\left[\mathrm{g} / \mathrm{m}^{3}\right]$, " $\mathrm{U}$ " is the wind speed $[\mathrm{m} / \mathrm{h}]$, "V" is the turbulent mixing volume $\left[\mathrm{m}^{3}\right]$ caused by the motion of the trucks on the expressway, $\mathrm{Q}_{\mathrm{T}}$ is the total truck flow [truck/h], and $\mathrm{K}_{\mathrm{T}}$ is the total truck density [truck/mi]. The turbulent mixing volume "V" is calculated by multiplying the turbulent area " $\mathrm{A}$ " behind the trucks by the length of the road covered by the selected wind sectors $\left(130^{\circ}\right.$ wind sector for each bound). Previous wind tunnel analysis has found that the turbulent area " $\mathrm{A}$ " $\left[\mathrm{m}^{2}\right]$ was dependent on the speed of the trucks and is given by equation 2 for the 2-truck configuration (see reference 18):

$$
\mathrm{A}=0.0028 \times \mathrm{SPD}^{2}-0.6177 \times \mathrm{SPD}+45.678
$$

Where "SPD" is the trucks speed [mi/h].

The estimated $\mathrm{PM}_{2.5}$ emission factor " $\mathrm{E}$ " $[\mathrm{g} / \mathrm{mi}]$ is calculated using the TAQModel (equation 3) developed using the Borman Expressway data and is given by:

$$
E=\left(0.0095 \times A c c^{2}+0.0022 \times A c c+5 \times 10^{-6} \times S P D^{2}-0.0005 \times S P D+0.0245\right) \times K_{T}
$$

Where "Acc" is the average acceleration $\left[\mathrm{m} / \mathrm{s}^{2}\right]$ on I-65, "SPD" is the average truck speed [mi/h] on I-65, and $\mathrm{K}_{\mathrm{T}}$ is the total truck density [truck/mi].

Figure 5 shows both the measured and calculated $\mathrm{PM}_{2.5}$ emission factors as a function of speed on I-65 for the period of May 31, 2006 to June 19, 2006. As shown in figure 5, the TAQ-Model performed well in estimating the measured $\mathrm{PM}_{2.5}$ emission factors for the speed range 50 to $65 \mathrm{mi} / \mathrm{h}$. However, at speeds greater than $65 \mathrm{mi} / \mathrm{h}$ (the upper free flow region), the TAQ-model has over estimated the measured emission factors. Similar behavior of the TAQ-model has been observed previously on the Borman Expressway, figure 6, where the TAQ-model performed well during congestions while over estimated during free flow, figure 6. Unfortunately, I-65 traffic has not experienced 
significant congested conditions to show on the data (speeds lower than $30 \mathrm{mi} / \mathrm{h}$ ). Note that the speed limit on I-65 is $70 \mathrm{mi} / \mathrm{h}$ compared to $55 \mathrm{mi} / \mathrm{h}$ on the Borman expressway, which explains the extra higher-speed range covered by the I-65 data.

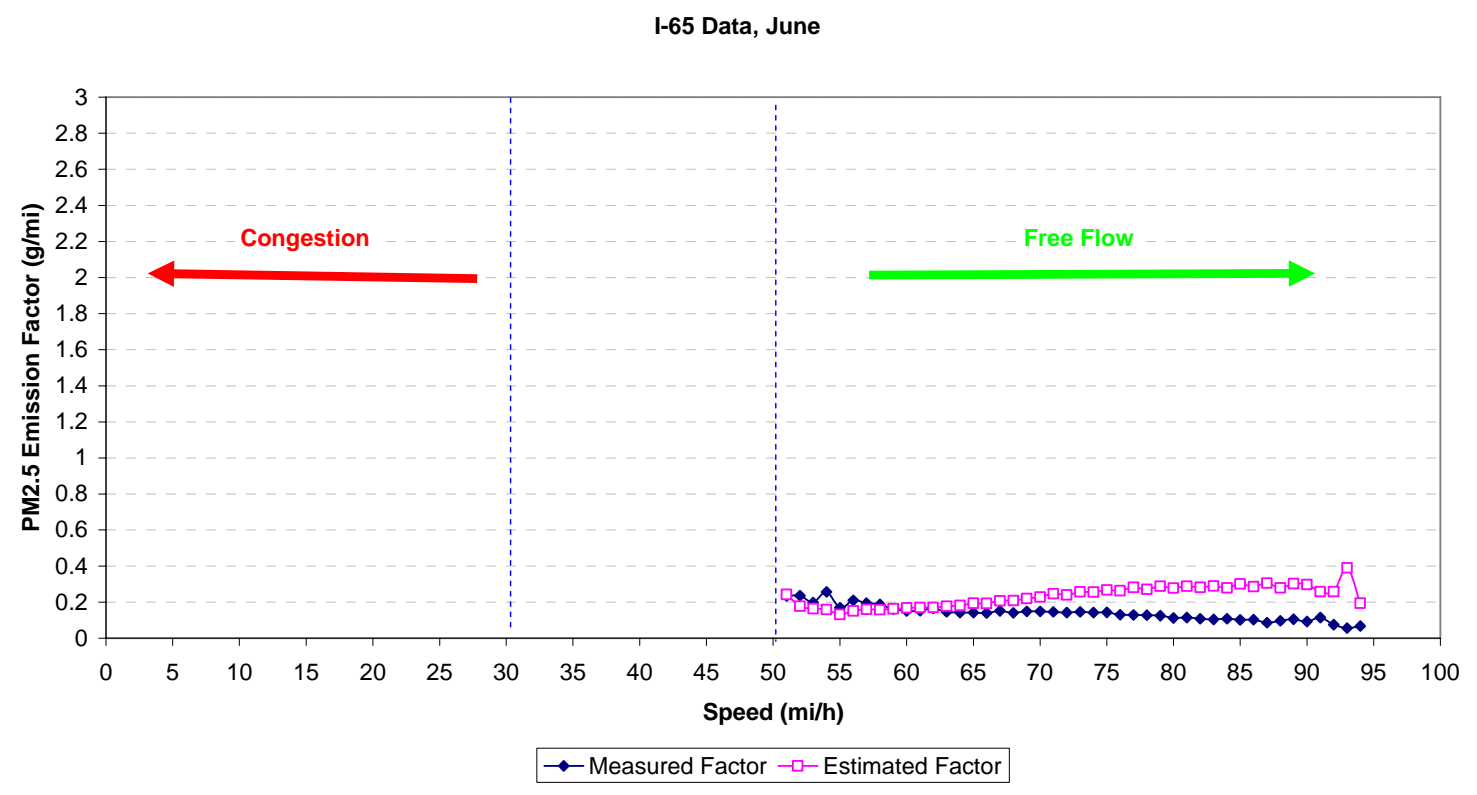

Figure 5. Measured and estimated $\mathrm{PM}_{2.5}$ emission factors on I-65, June 2006.

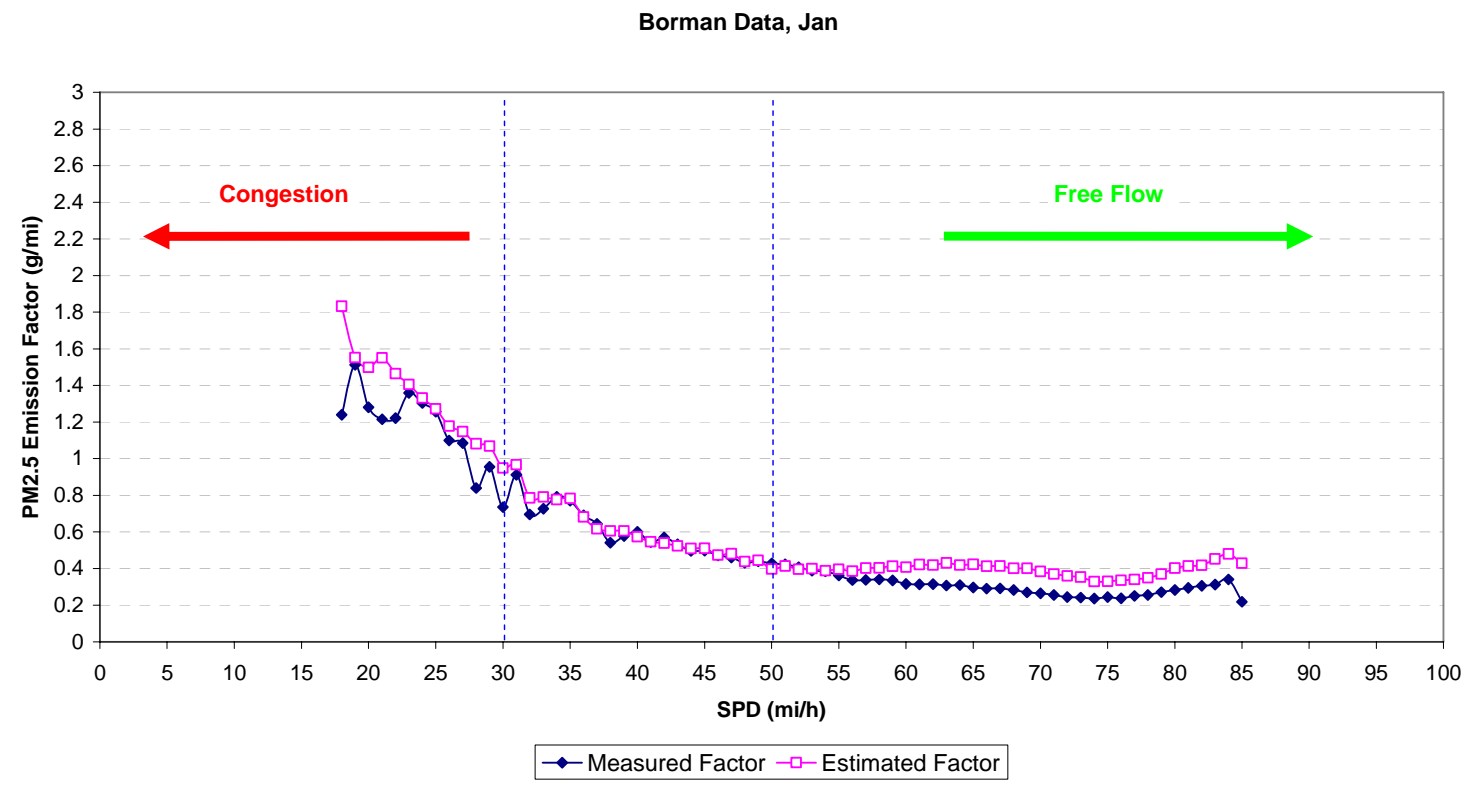

Figure 6. Measured and estimated $\mathrm{PM}_{2.5}$ emission factors on the Borman Expressway, January 2006. 
I-65 Traffic Data Analysis: Traffic data on I-65 were analyzed for the period of May 31, 2006 to June 19, 2006 and compared to the traffic characteristics on the Borman Expressway. As shown in figure 7, the traffic flow on I-65 has not experienced significant congestions compared to the Borman Expressway traffic figure 8.

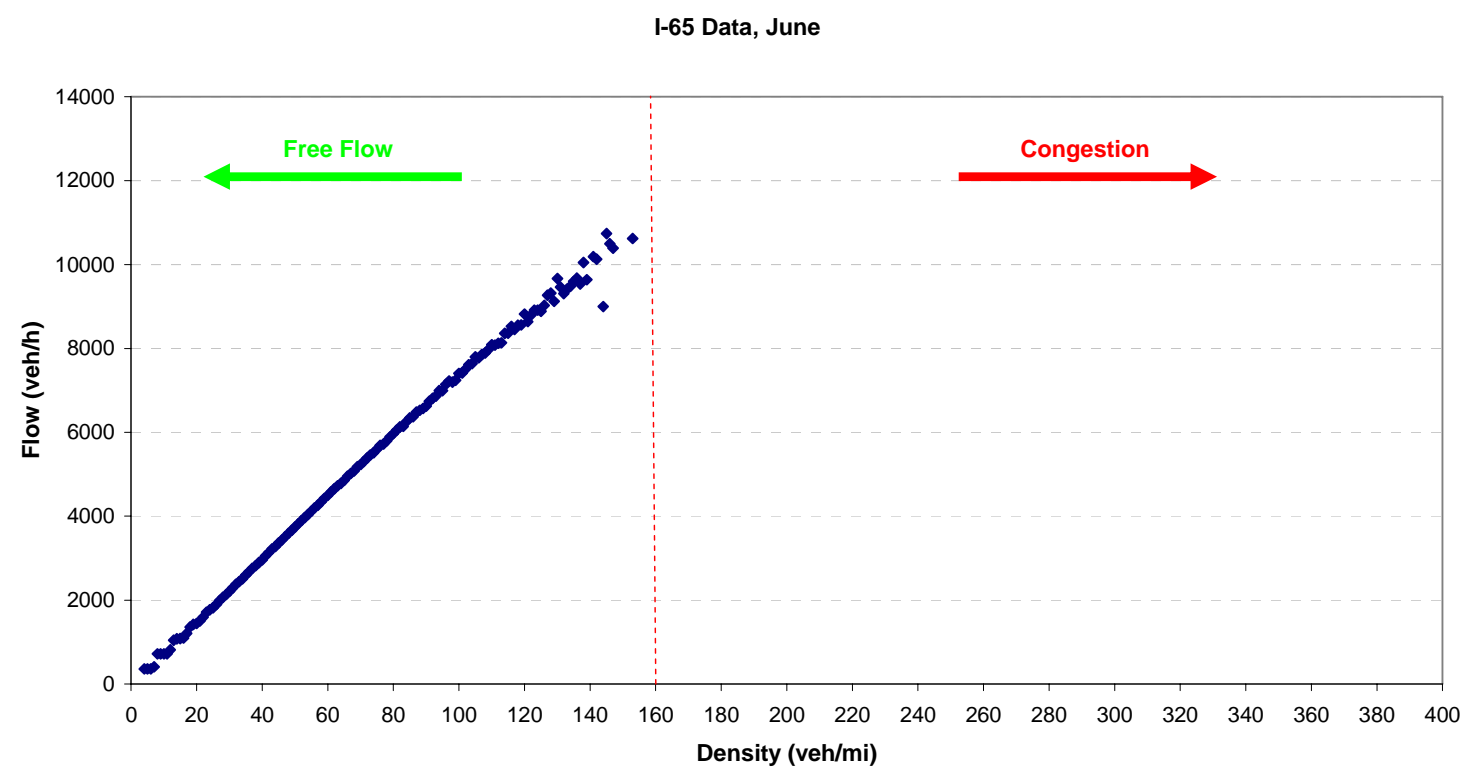

Figure 7. Traffic flow versus traffic density on I-65, June 2006.

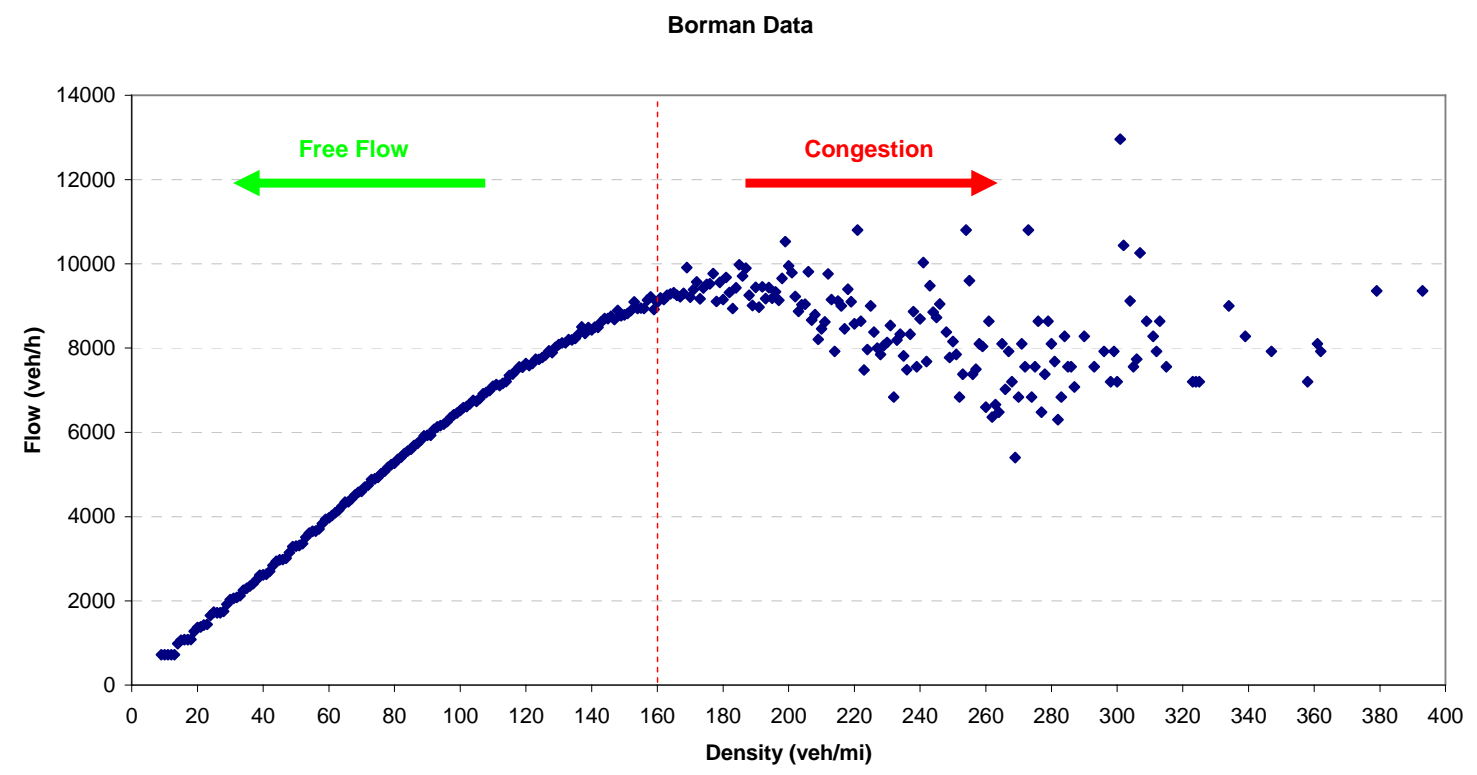

Figure 8. Traffic flow versus traffic density on the Borman Expressway, February 2006. 
Similar conclusion is deduced from figures 9 and 10 showing the traffic flow as a function of road occupancy for both I-65 and the Borman Expressway.

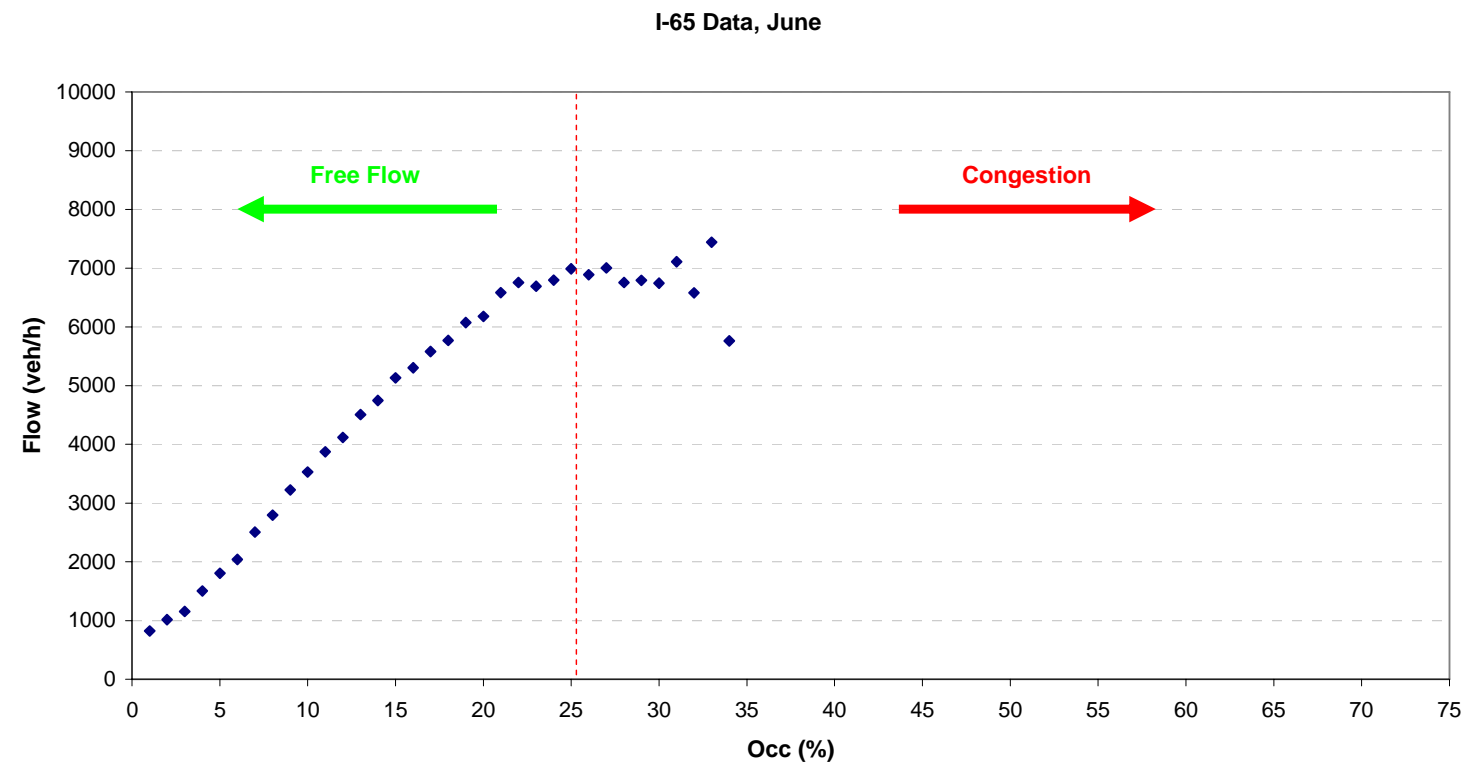

Figure 9. Traffic flow versus road occupancy on I-65, June 2006.

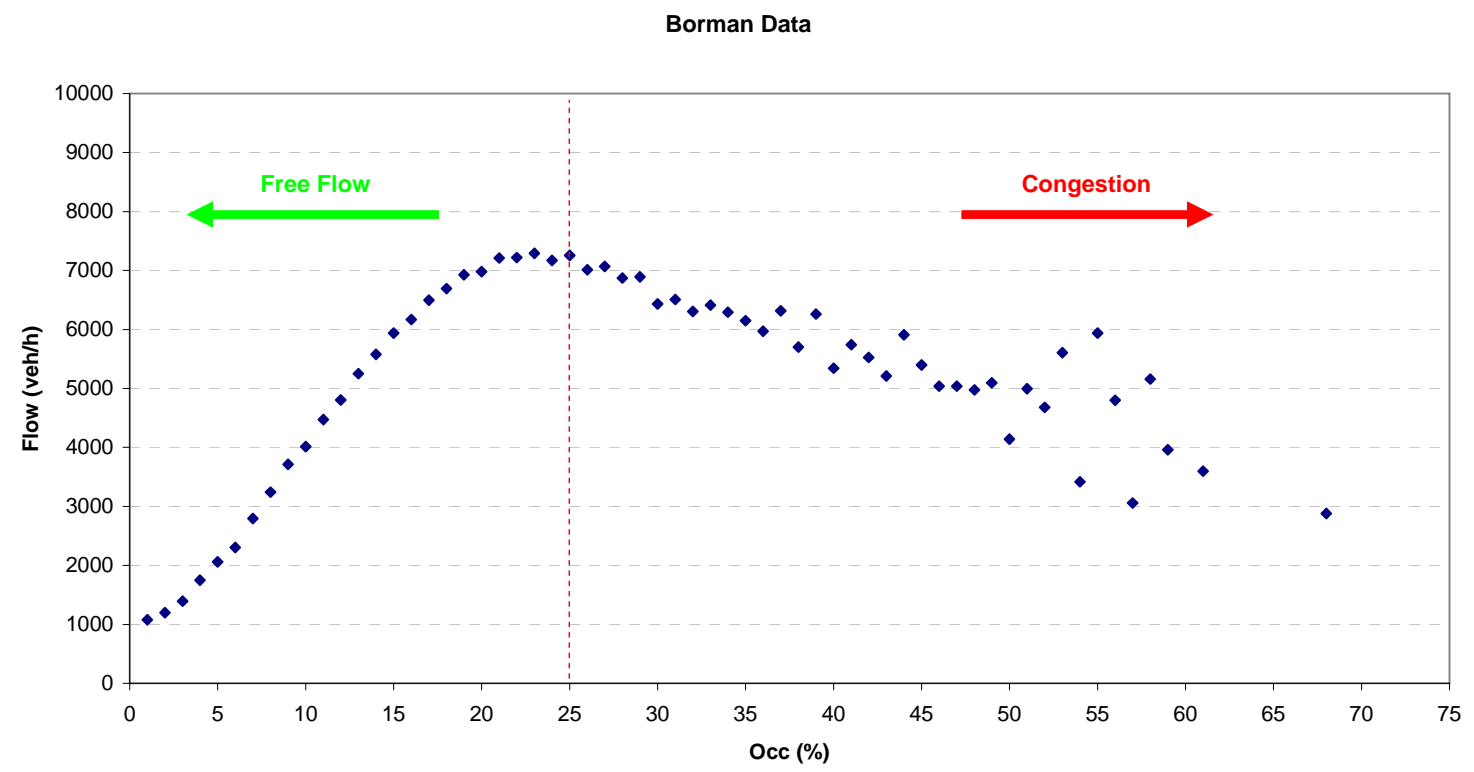

Figure 10. Traffic flow versus road occupancy on the Borman Expressway, February 2006. 
I-65 Analysis Conclusion: Data collected on I-65 has shown that the TAQ-Model applied to I-65 traffic shows similar characteristics to what have been seen on the Borman Expressway in terms of producing better predictions of $\mathrm{PM}_{2.5}$ emission factors at low speeds (during congestions) compared to higher speeds. However, more data is needed to be collected during congested periods to quantitatively verify this claim. Measuring data at other locations near major cities, such as I-465, may provide the opportunity to collect data during significant congestion episodes.

\section{3) I-465/Indianapolis Air Sampling Locations:}

Several sites on the different Indianapolis expressways have been checked on July 6 , 2006 on the afternoon rush hour (5:00 PM) to find the best location of the air sampling vans in the Indianapolis area. I-65, and I-70 inside the I-465 ring (figure 11) have been checked as well as portions of I-465 (I-465 has been checked earlier on previous date and potential locations have been checked again this time as well as on July 18 for photo and contact information gathering).

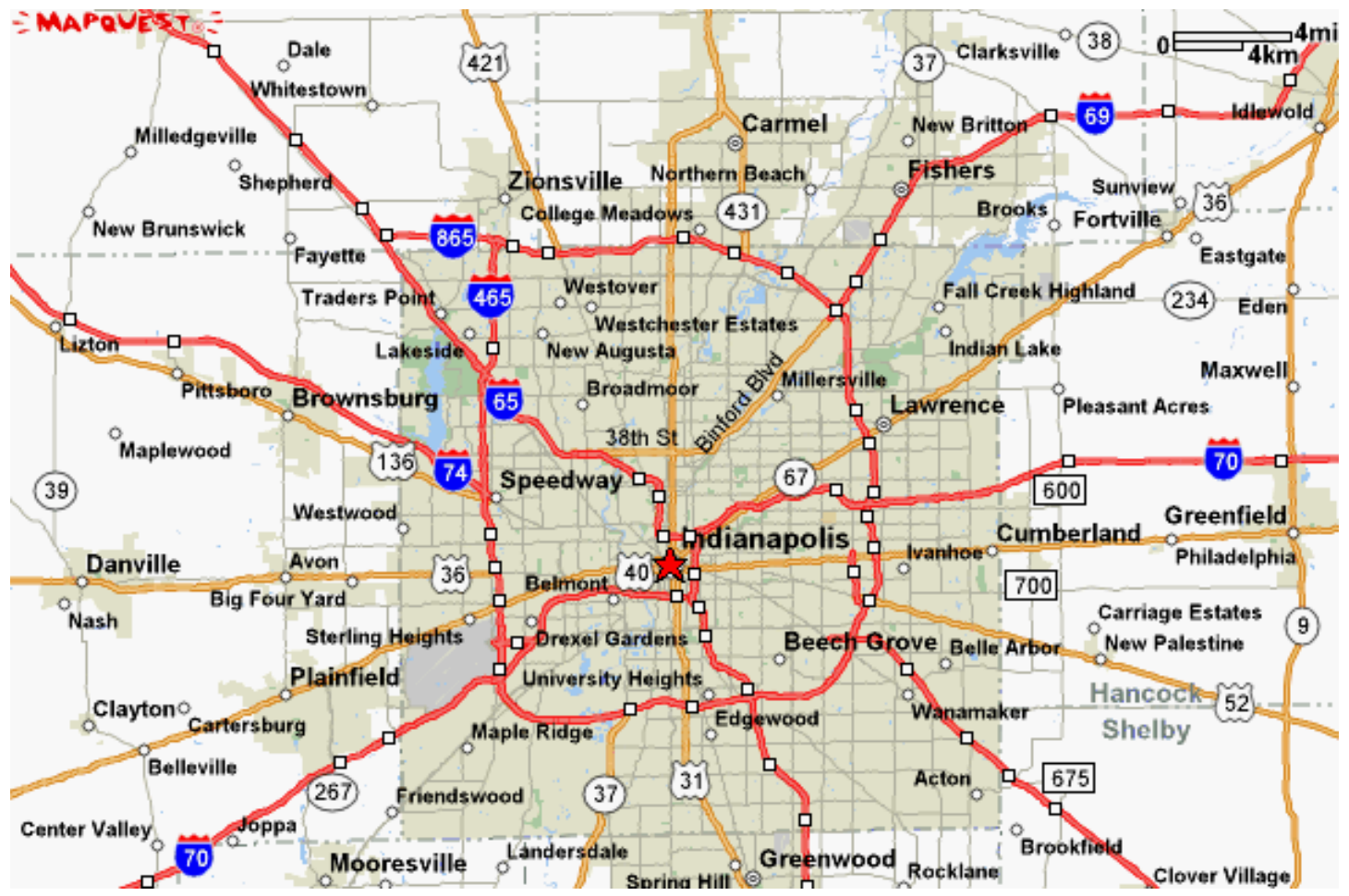

Figure 11. Map of the expressways checked in the Indianapolis area (I-65, I-70 and I465). 
The following table, table 2, summarizes the findings of the search trip:

Table 2. Summary of the I-65 location search.

\begin{tabular}{|c|c|}
\hline Highway Link & Notes \\
\hline $\mathrm{I}-65$ & $\begin{array}{l}\text { No good locations have been found on the I- } 65 \text { expressway } \\
\text { stretching inside the I- } 465 \text { ring. }\end{array}$ \\
\hline I-70 West of Indy & $\begin{array}{l}\text { mm 78: Good truck count, houses backyards, full of trees, } \\
\text { no congestions, locations are around } 50 \text { feet away from } \\
\text { expressway. Expressway is } 3 \text { lanes each way. } \\
\text { mm 85: Good truck count, houses on the west bound and } \\
\text { businesses on the east bound, no congestions. Expressway is } \\
4 \text { lanes each way. }\end{array}$ \\
\hline I-465 South of Indy & $\begin{array}{l}\text { mm 49: Good truck count, INDOT road service facility on } \\
\text { the east bound, electric power facility on the west bound, } \\
\text { both locations are around } 100 \text { feet away from the } \\
\text { expressway. Expressway is } 3 \text { lanes each way. } \\
\text { mm } 50 \text { and mm 51: BEST LOCATIONS, good truck count, } \\
\text { no congestions, } 3 \text { lanes each way, boat/RV dealership and } \\
\text { storage area on the west bound (near mm 50), tool rental } \\
\text { place, carpet store and material storage on the east bound } \\
\text { (near mm 51). All locations on both bounds are less than } 50 \\
\text { feet away from highway. }\end{array}$ \\
\hline I-465 West of Indy & $\begin{array}{l}\mathrm{mm} 11 \text { and mm12: Tool rental pace and company parking } \\
\text { lot on northbound (mm } 11) \text {, car rental parking lot (Avis) on } \\
\text { the south side (mm } 12) \text {. Both locations are around } 150 \text { feet } \\
\text { way from expressway near the airport. }\end{array}$ \\
\hline
\end{tabular}

As mentioned in the summary, the best locations were found to be on I-465 near mile markers 50 and 51 south of Indianapolis. The following is a detailed description of these locations along with the contact information of people responsible for the businesses located near the expressway. 
Best Air Sampling Locations, I-465 South of Indy: Figure 12 shows the location of the best found air sampling sites in south of Indianapolis, near mile markers, mm 50 and $\mathrm{mm} 51$ (Emerson Ave. exit), on Elmwood Ave. (west bound location) and Victory Dr. (east bound location).

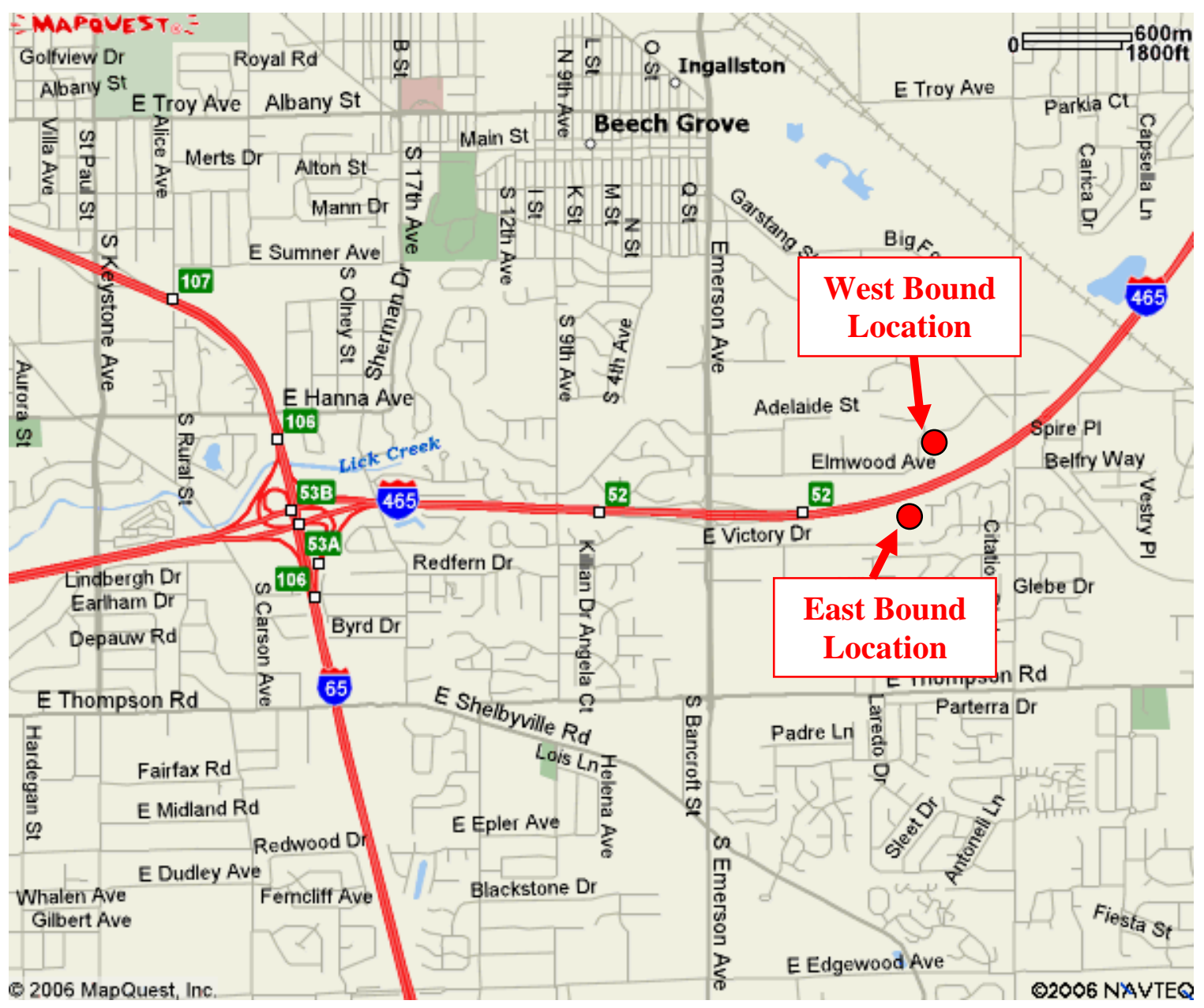

Figure 12. Best air sampling locations found south of Indianapolis.

The I-465 expressway south of Indianapolis had good truck count comparable to I-65, with speed limit of $55 \mathrm{mi} / \mathrm{h}$ similar to the one on the Borman Expressway. No significant congestions were observed, as well as there were no road constructions near the sites. The east bound locations are shown on figures 13-a, -b, and -c. The locations were less than 50 feet away from the expressway. 

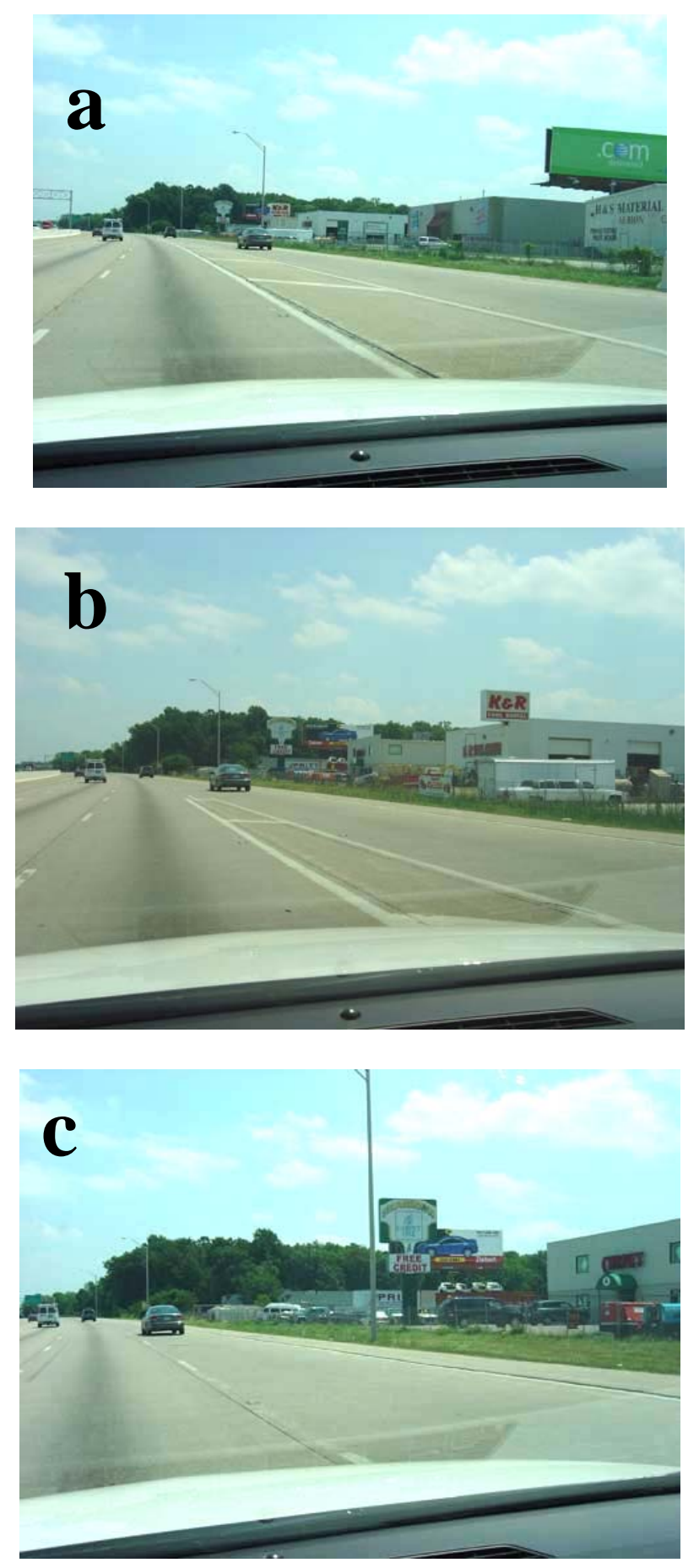

Figure 13. Locations on I-465 East bound near mm 51 south of Indianapolis. a) H\&S Parking lot, b) K\&R parking lot, and c) Carpet One Store parking lot. 
Similar locations were also found for the I-465 west bound traffic near mm 51. Figures 14-a, and -b show the possible locations on the west bound that were a boat/RV dealer as well as a public storage area.

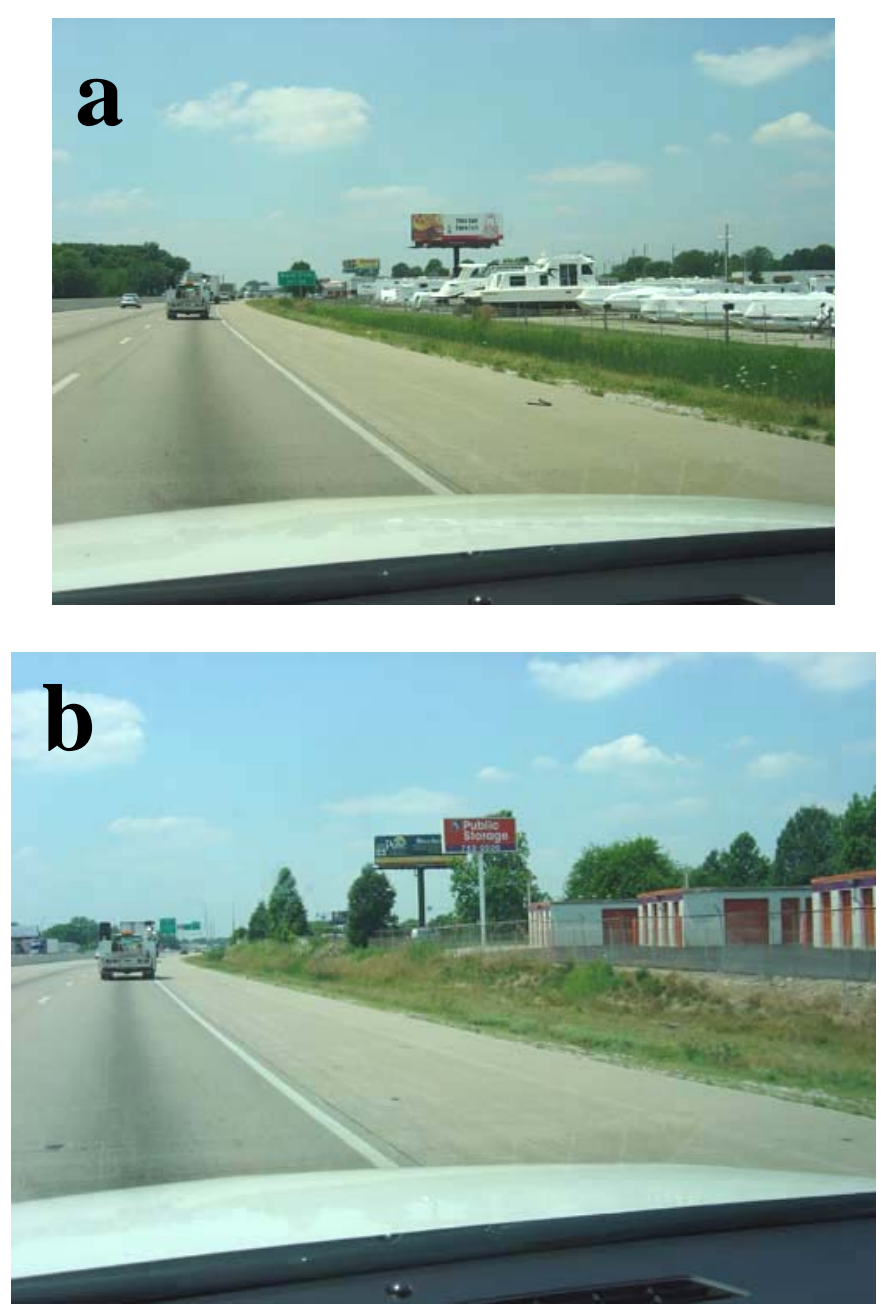

Figure 14. Locations on I-465 West bound. a) Marine Boat dealer, b) public storage. 
The final locations were chosen at the RV-Store and the H\&S Materials locations. Figure 15 and 16 show the installed monitoring stations at the site.

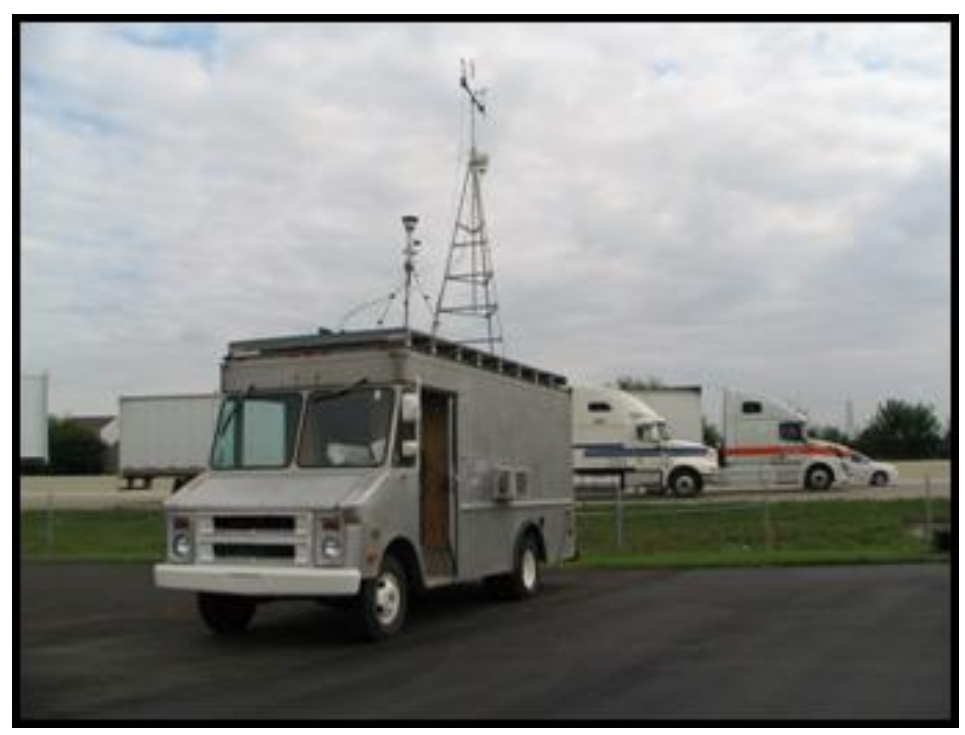

Figure 15. The RV-Location north of I-465, Indianapolis, IN.

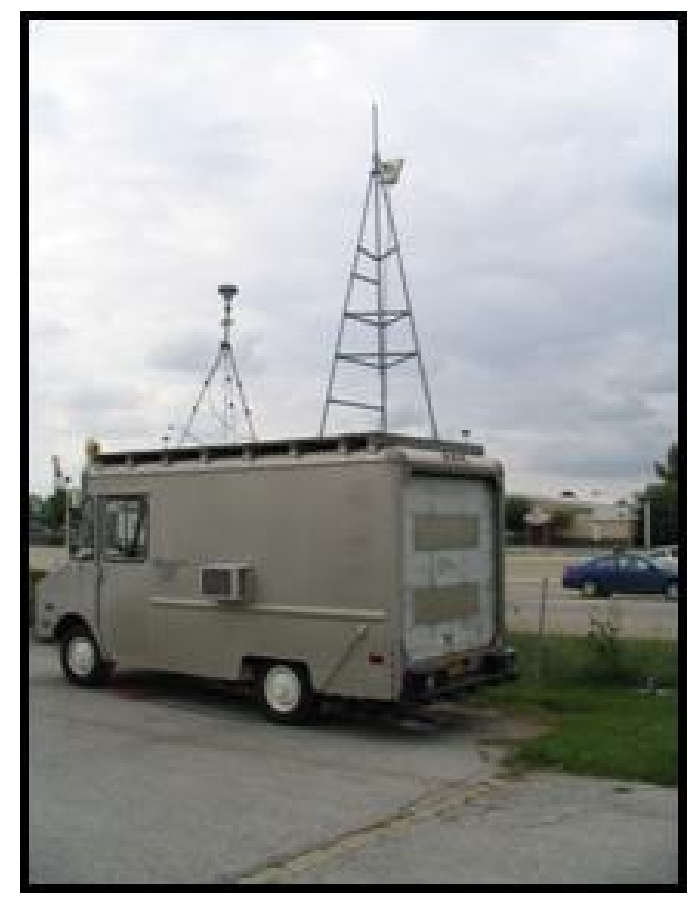

Figure 16. The H\&S-Location south of I-465, Indianapolis, IN. 
Measured and Estimated Data Analysis for I-465: $\mathrm{PM}_{2.5}$ emission factors [g/mi] of I-465 have been calculated from measured data as well as estimated using the Borman Traffic-Air-Quality Model (TAQ-Model), equations 1 through 3, then the results were compared to test the applicability of the TAQ model to the different highways in Midwest states.

Similar to what have been observed on the I-65 data analysis, the TAQ model performed well in estimating the PM2.5 emissions when compared to the measured values, figure 17. Although there were no significant congestions on I-465 during the data collection period, however the lower speed limits on I-465 $(55 \mathrm{mi} / \mathrm{h})$ allowed the model to estimate the PM2.5 emissions in the slow-speeds-region as shown in figure 17.

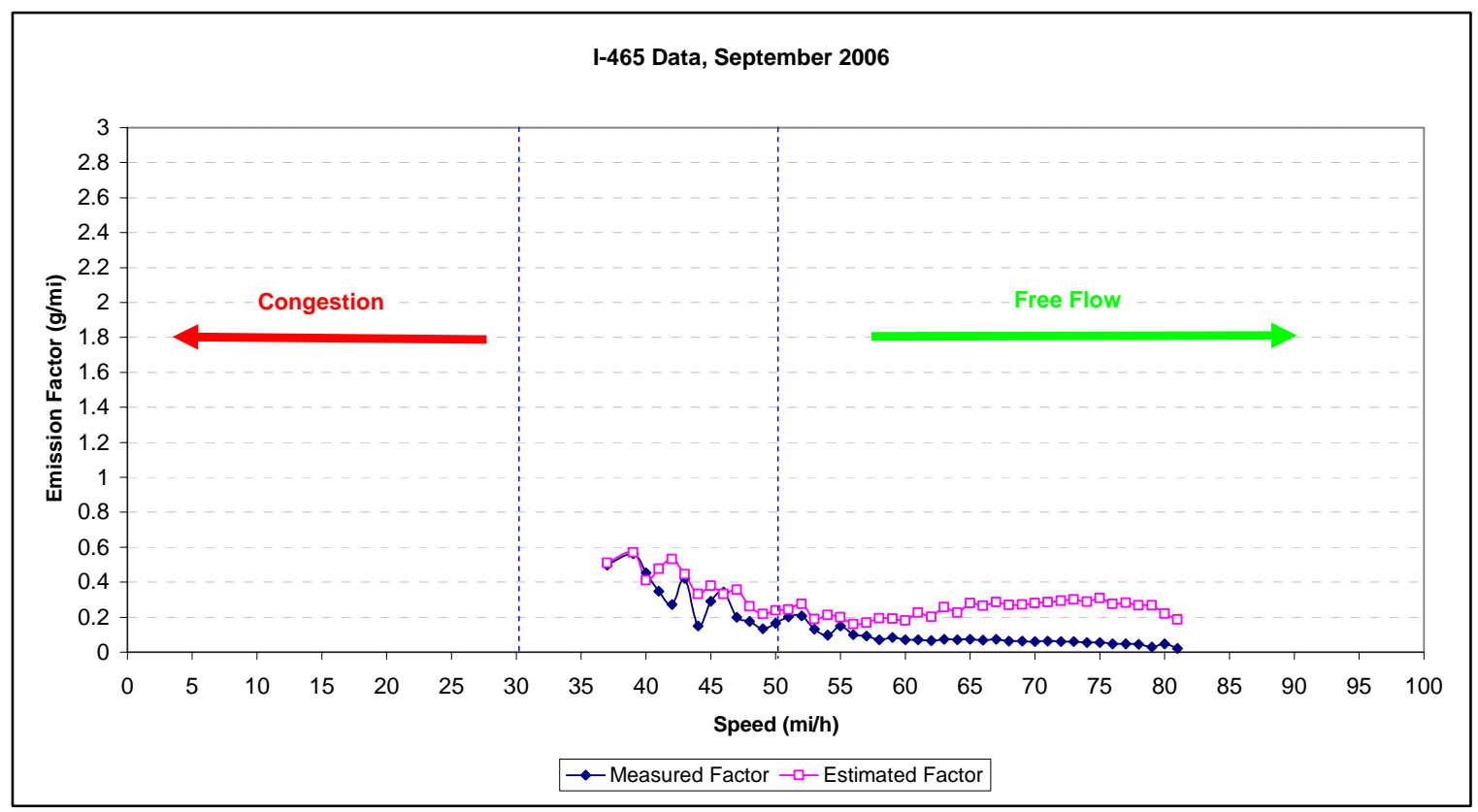

Figure 17. Measured and estimated $\mathrm{PM}_{2.5}$ emission factors on I-465, September 2006.

The I-65 and the I-465 data collection and analysis have shown the ability of the TAQ model to successfully estimate the PM2.5 emission factors based solely on traffic data. The following step is to implement the TAQ mode to a real-time case where traffic conditions are monitored on an expressway and the impact of traffic conditions on air quality is estimated. 
TRAFFIC PERFORMANCE MEASURES; THE NORMALIZED TRAVEL TIME

Traffic condition in general are described using the Highway Capacity Manual (HCM2000) that identifies the Level Of Service (LOS) of the highway. LOS is a "quantized" parameter that is based on the density of passenger vehicles per lane, their speed, and flow rate. The LOS is divided into the following "quantized" levels ${ }^{[19]}$ :

Level A: Complete free flow conditions, where vehicles are unimpaired in their ability to maneuver.

Level B: Slight restrictions on the road, while vehicles maintain their free flow speeds, an overall reasonable free flow condition.

Level C: Speeds are at or slightly lower than the free flow speeds, however, there is a noticeable restriction to vehicles' ability to maneuver.

Level D: Speeds are decreased compared to free flow speeds with a major increase in vehicle densities due to the rapid increase in the vehicle flow; gaps (space headways) decrease significantly at this level.

Level E: Low speeds, where there is virtually no usable gaps in the highway, therefore any restriction to the traffic stream such as entering traffic or incidents may result in traffic-queuing.

Level F: Complete breakdown in the traffic flow; long-term queue formations occur.

Although such LOS traffic levels have been widely and successfully used, it is suggested for this Borman Expressway air quality research to use a more "continuous" and simpler traffic parameter to describe the traffic flow along a segment of a highway rather than the quantized LOS. Such parameter referred to as the "normalized-traveltime" or TRN.

The normalized-travel-time is estimated as follows:

$$
T R N=\frac{\text { traveltime }}{\text { traveltime@ flowspeed }}
$$

where travel-time is the time needed to travel a segment length of the highway, and travel-time@flow-speed is the travel time of the same segment for vehicles traveling at the speed limit. Based on such definition (equation 4); for TRN values ranging $0<\mathrm{TRN}$ $<1$, traffic is freely moving at speeds higher than the speed limit, where the faster the 
traffic moves, the smaller the TRN value. On the other hand, signs of congestion as well as traffic jams occur for the TRN range of $1<\mathrm{TRN}$, where the slower the traffic moves, the bigger the TRN value. At TRN = 1, the traffic is moving exactly at the speed limit. Figure 18 is a schematic diagram that summarizes the TRN description of the traffic flow.

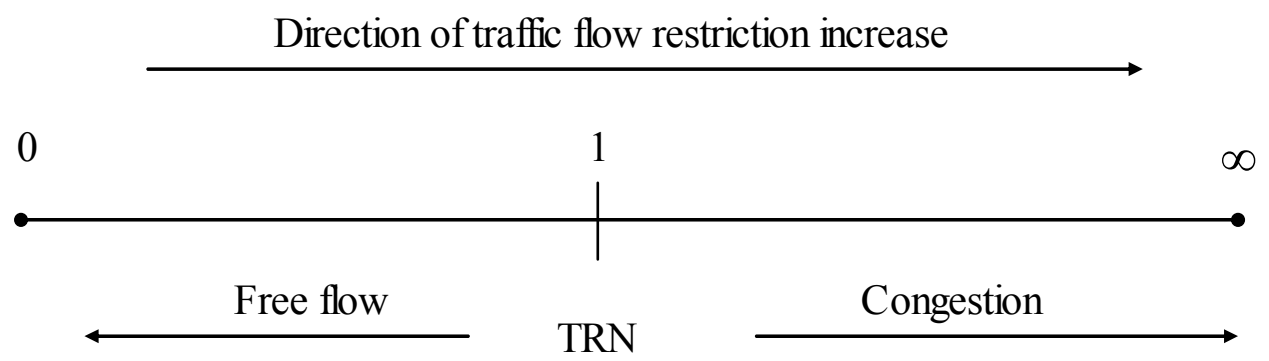

Figure 18. A schematic diagram showing the concept of the normalized travel time factor (TRN).

Figure 19 illustrates the TRN concept for the data collected during the WAVETRONIX $^{\mathrm{TM}}$ traffic sensors calibration tests in March 2005. The figure shows the TRN values for the data collected at the center lane flow of the Borman Expressway's west bound. As shown in the figure, congestion occurred between 10:00 AM and 11:00 AM, where the severity of the congestion reached up to 8.6 times worse than the case of speed-limit-flow (i.e. traffic is moving at about $10 \mathrm{~km} / \mathrm{hr}$ or $6.4 \mathrm{mi} / \mathrm{hr}$ ). On the other hand, traffic was flowing normally near the speed limit value during the period of 2:30 PM to 3:30 PM (14:30 to 15:30) (TRN values between 0.89 and 1.3). The travel times estimated in this Borman Expressway study are based on time-stamped speeds measured by the WAVETRONIX $^{\mathrm{TM}}$ side-fire microwave traffic sensors for a road link of $0.5 \mathrm{~km}(\sim 0.3$ miles) downstream from the sensors and for an estimated shockwave speed of $20 \mathrm{~km} / \mathrm{hr}$ $(\sim 12 \mathrm{mi} / \mathrm{hr})$ as illustrated by Coifman's algorithm ${ }^{[20]}$. 


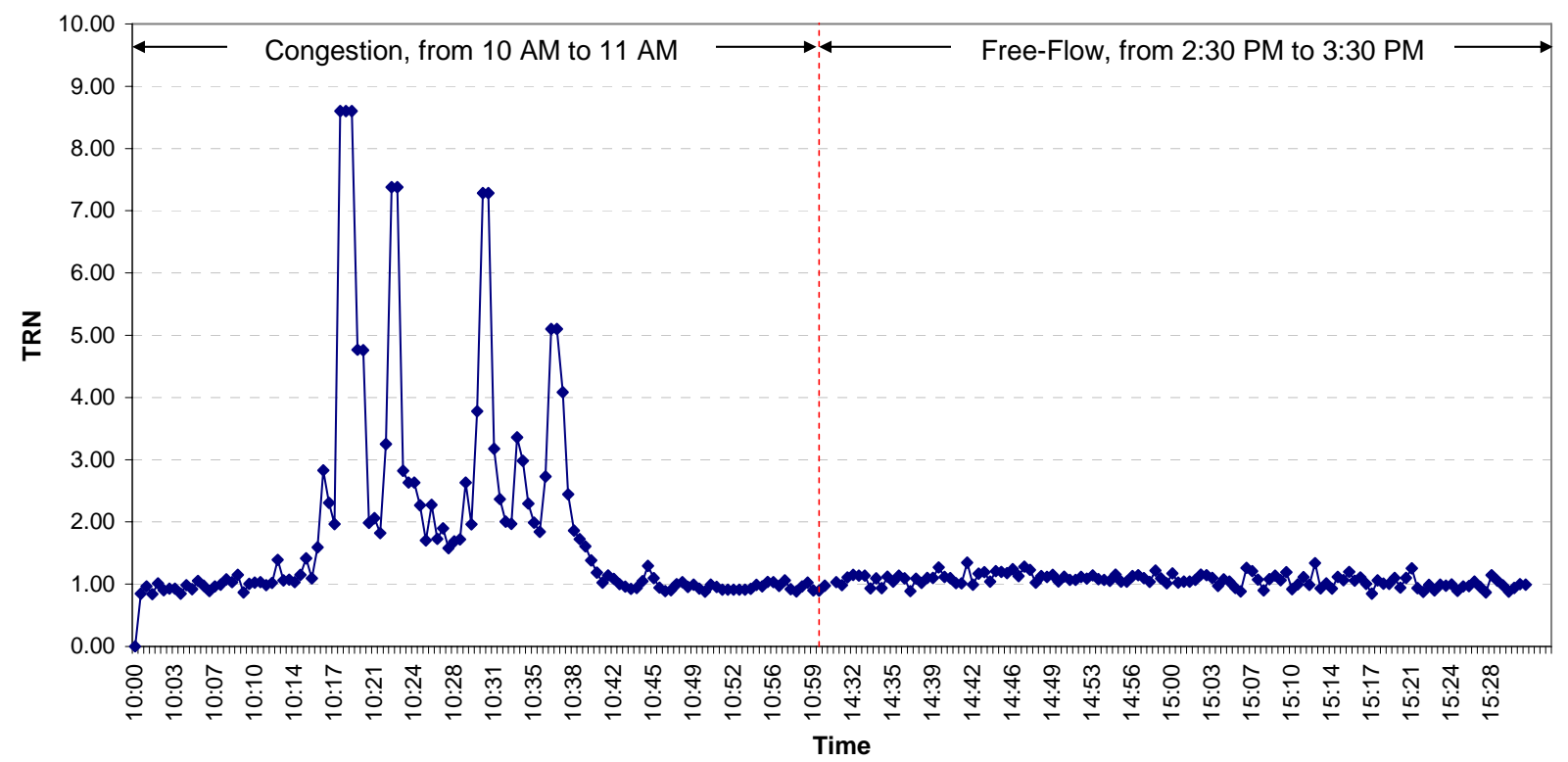

Figure 19. Normalized travel time (TRN) as a function of time during congestion and free flow for the west bound central lane of the Borman Expressway, March 15, 2005.

\section{PART II: THE BORMAN CASE STUDY}

This section presents three different case studies of how traffic congestion changes the fine particulate emission factor, hence affecting the local air quality next to an expressway. Figure 20 shows the normalized travel time factor (TRN) as a function on time of day for the Borman Expressway's east and west bounds on March 15, 2005. As shown in figure 20, the three chosen cases are for the periods; Case 1: 8:10-9:10 AM, Case 2: 10:00 - 11:00 AM, and Case 3: 2:45 - 3:45 PM. In Case 1; traffic flowed freely on both the east and west bounds of the Borman expressway, maintaining a TRN value ranging between 0.75 and $1.0(117 \mathrm{~km} / \mathrm{hr}$, and $88 \mathrm{~km} / \mathrm{hr} ; 73$ and $55 \mathrm{mi} / \mathrm{hr}$; respectively). Case 2 on the other hand represents a congestion case on the west bound while the east bound maintained normal flow as indicated by the average TRN values of both bounds. Case 3 represents the opposite; a congestion on the east bound while the west bound maintained a relatively free flow with the exception of a short-lived TRN peak $(T R N=$ 1.3) at 3:10 PM. 


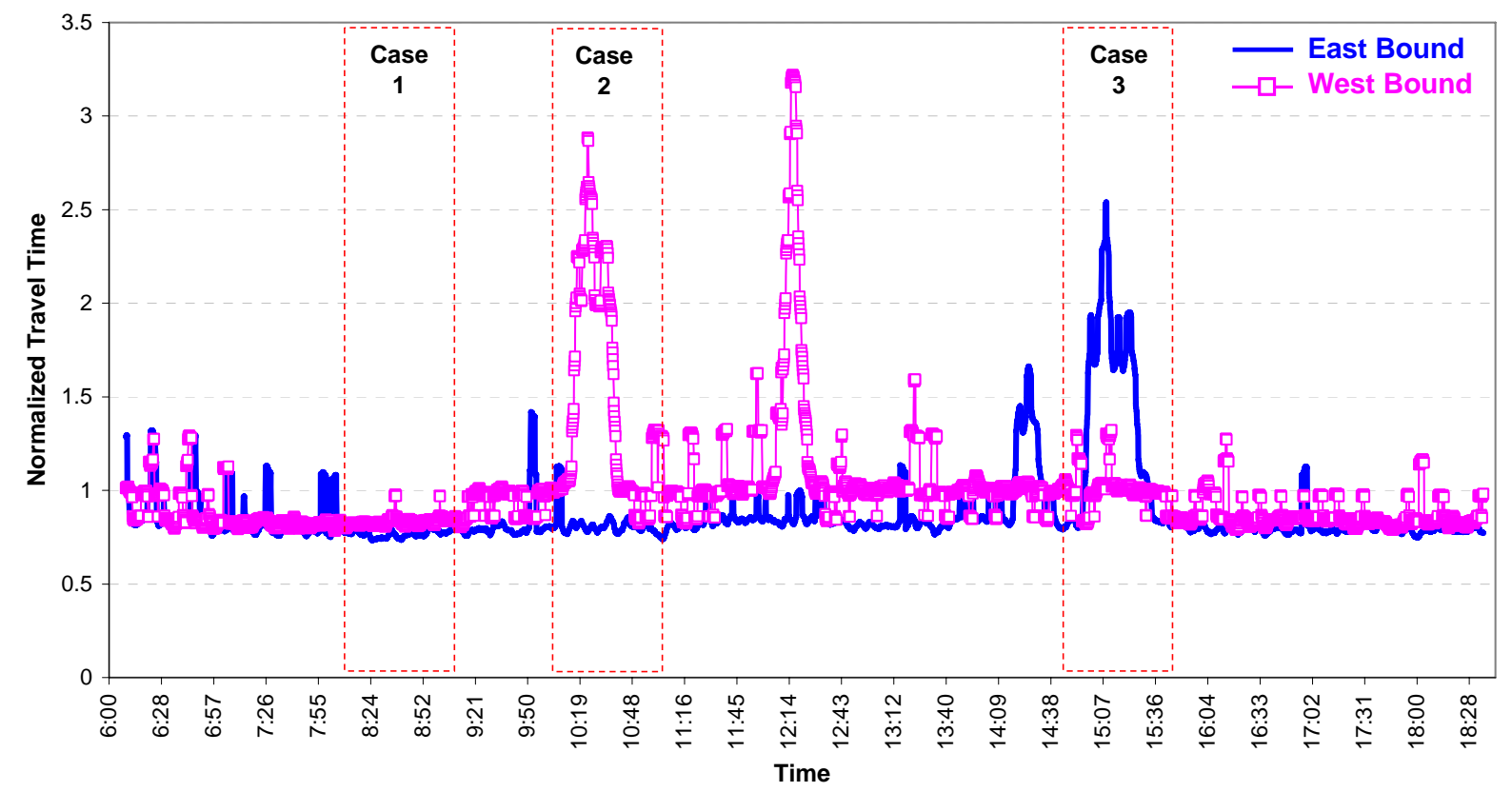

Figure 20. Normalized travel time factor (TRN) as a function of time for both the east and west bounds of the Borman Expressway, 3/15/2005.

The contribution of each bound (travel direction) to the fine particulates $\left(\mathrm{PM}_{2.5}\right)$ emission factors corresponding to the three cases mentioned above were estimated using the Traffic-Air Quality Model (TAQ Model in MKS units ${ }^{[18]}$ ) as follows:

$$
E=\left(0.0095 \times A c c^{2}+0.0022 \times A c c+2 \times 10^{-6} \times S P D^{2}-0.0003 \times S P D+0.0245\right) \times k_{T}
$$

Where ' $\mathrm{E}$ ' is the $\mathrm{PM}_{2.5}$ emission factor $[\mathrm{g} / \mathrm{km}]$, 'Acc' is the average traffic acceleration/deceleration on each bound $\left[\mathrm{m} / \mathrm{sec}^{2}\right]$, 'SPD' is the average traffic speed on each bound $[\mathrm{km} / \mathrm{hr}]$, and $\mathrm{k}_{\mathrm{T}}$ is the total class- 9 truck densities on each bound [truck $\left./ \mathrm{km}\right]$.

The estimated $\mathrm{PM}_{2.5}$ emissions for each bound are shown in figure 21. As shown in figure 21, during normal traffic operations on the expressway, Case 1, both the east and west bounds contributed equally to the emission factors. However, in Case 2, the west bound traffic contributed on average six times more to the $\mathrm{PM}_{2.5}$ emissions than the east bound traffic. Case 3 on the other hand, shows that congestion on the east bound resulted in seven times more contribution to the $\mathrm{PM}_{2.5}$ emissions than the west bound where the traffic was moving freely. 


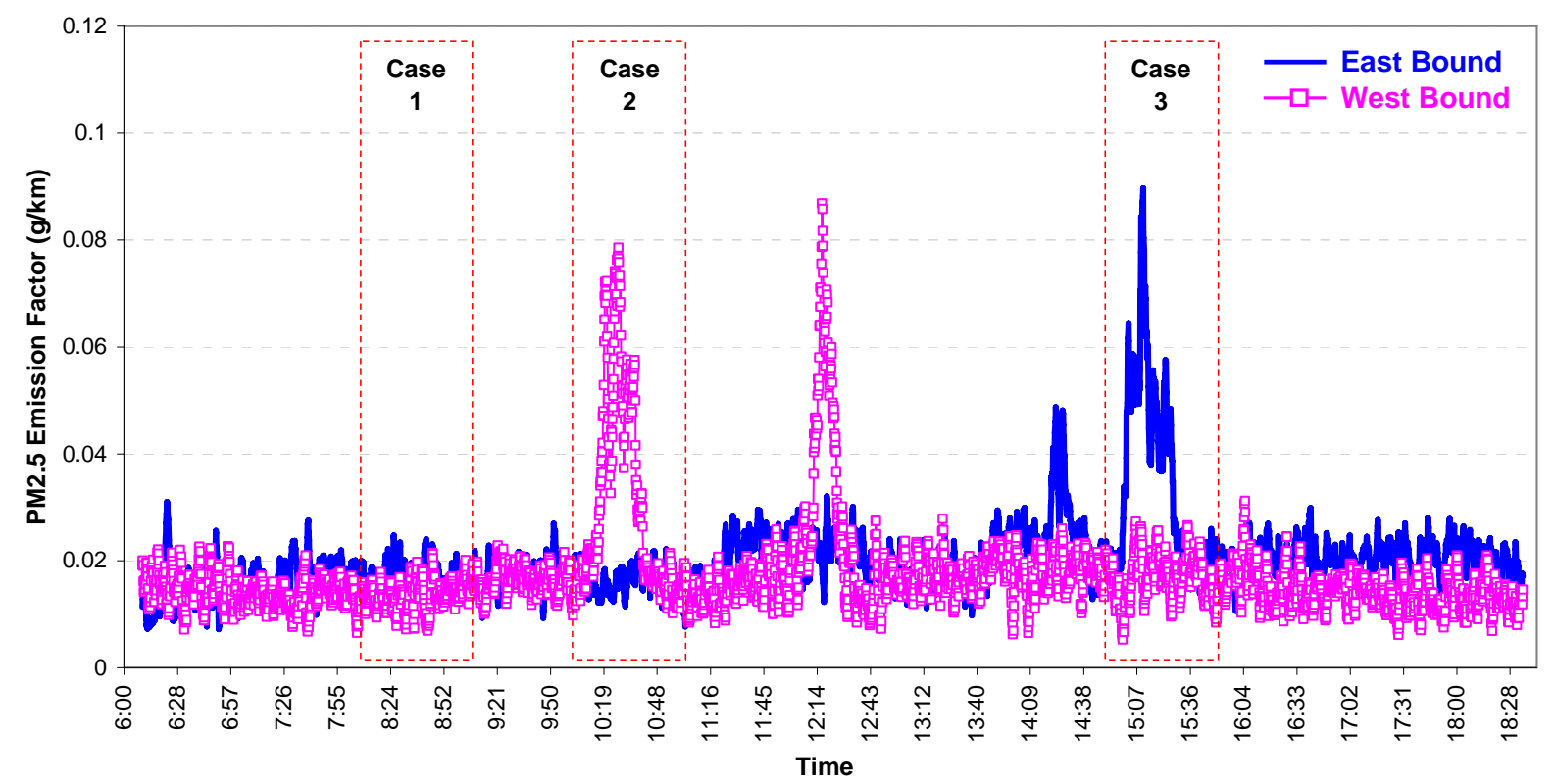

Figure 21. PM2.5 emission factors as a function of time for both the east and west bounds of the Borman Expressway, 3/15/2005. Curve is smoothed using a moving average function of order 10 .

Figures 22 through 24 show that the peaks in the $\mathrm{PM}_{2.5}$ emissions were not a direct result of the change in the fleet mix or the class-9 truck volume, but rather a result of the speed reduction due to traffic congestions on both the east and west bounds. Figure 22 shows the average traffic speeds on both bounds of the expressway with the reduction of speeds in cases 2 and 3 corresponding to the traffic jams as explained above. Figure 23 on the other hand shows that the class-9 truck flow (truck volume) on both bounds did not change significantly during the periods of these case studies and remained similar on both bounds. The fleet mix (the ratio of the number of class-9 trucks to the total number of vehicles) also did not show the congestion peaks of cases 2 and 3 as shown in figure 24. 


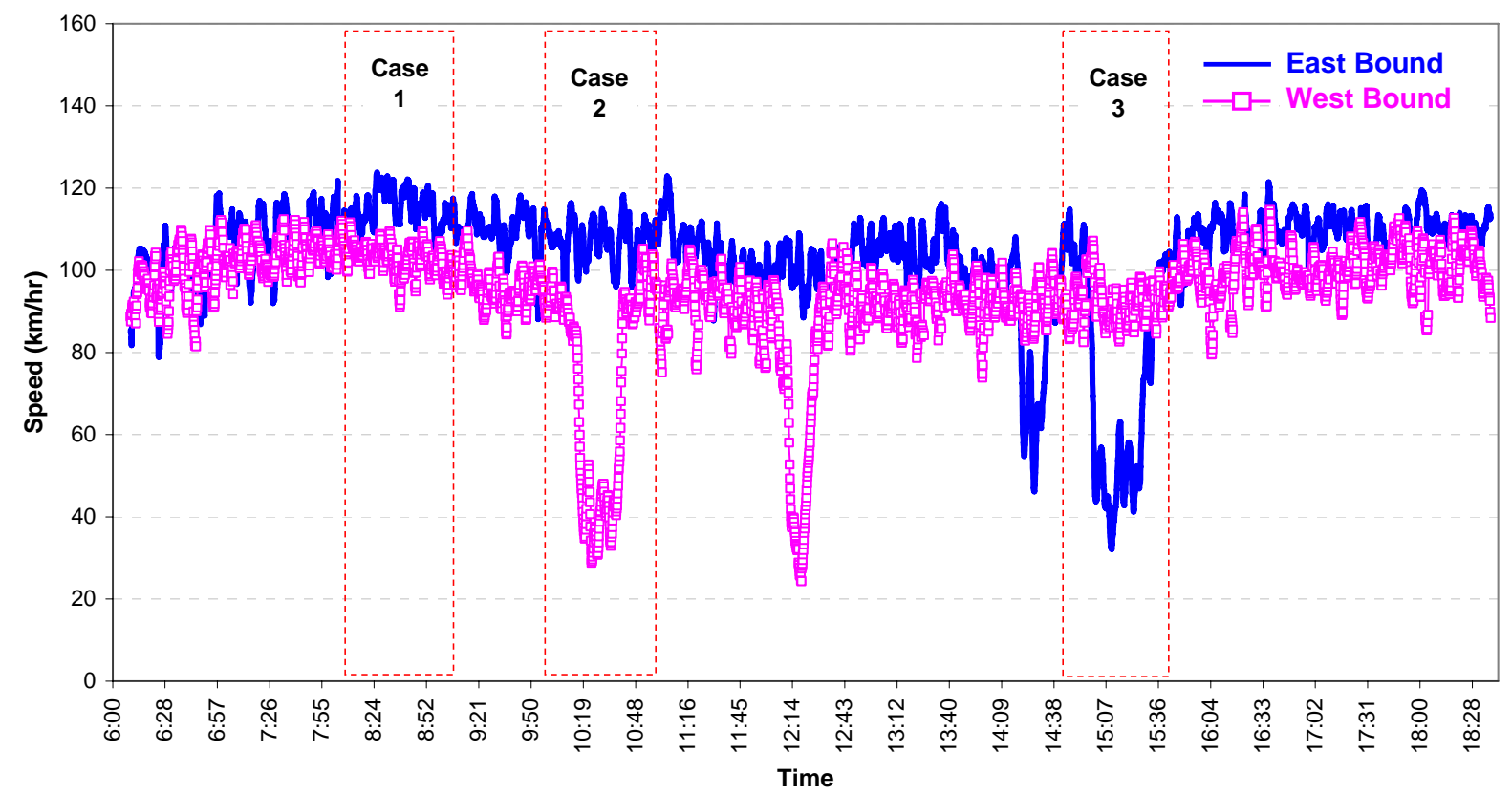

Figure 22. Average traffic speed as a function of time for both the east and west bounds of the Borman Expressway, 3/15/2005. Curve is smoothed using a moving average function of order 10 .

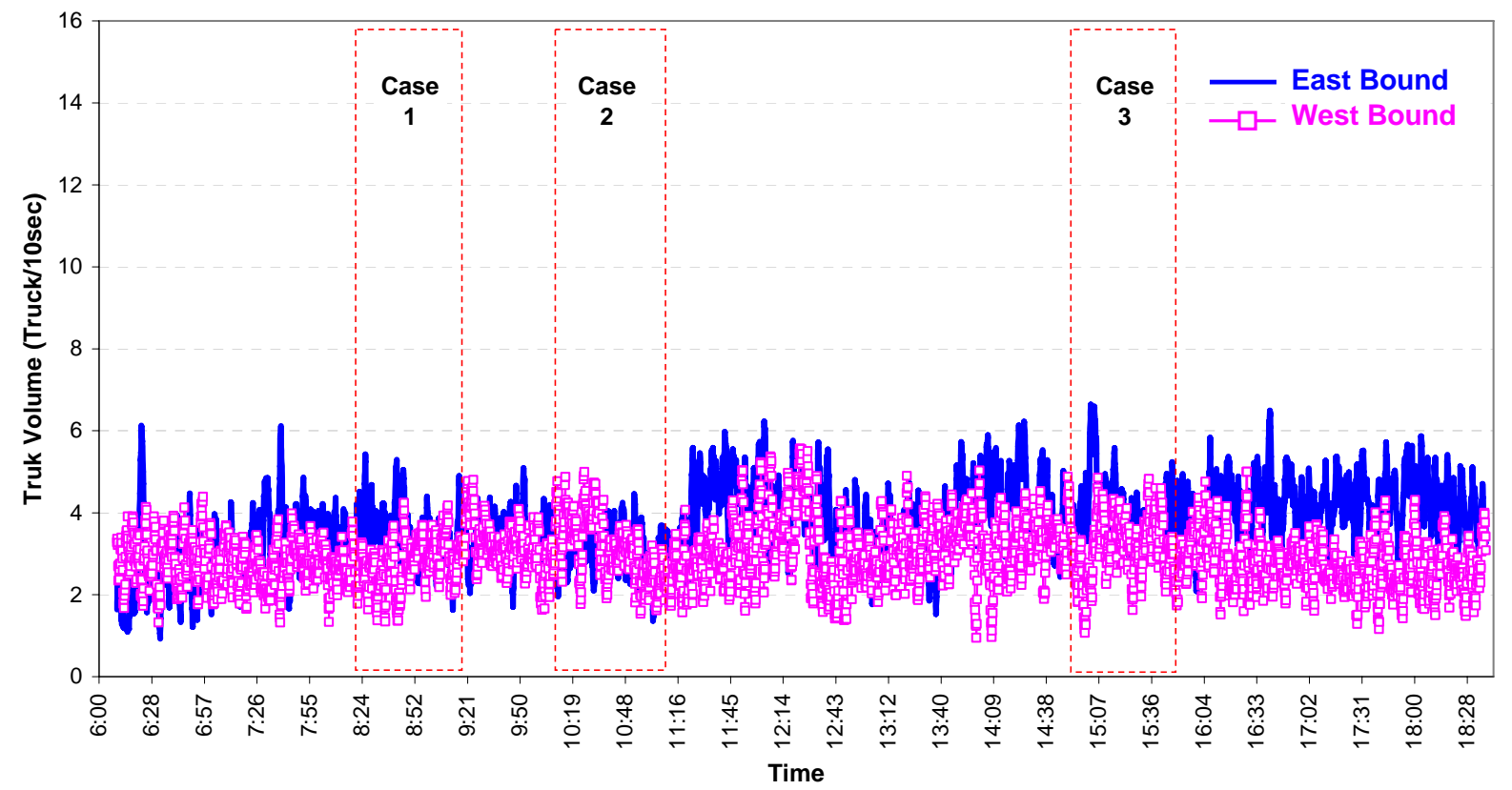

Figure 23. Total class-9 truck volume as a function of time for both the east and west bounds of the Borman Expressway, 3/15/2005. Curve is smoothed using a moving average function of order 10 . 


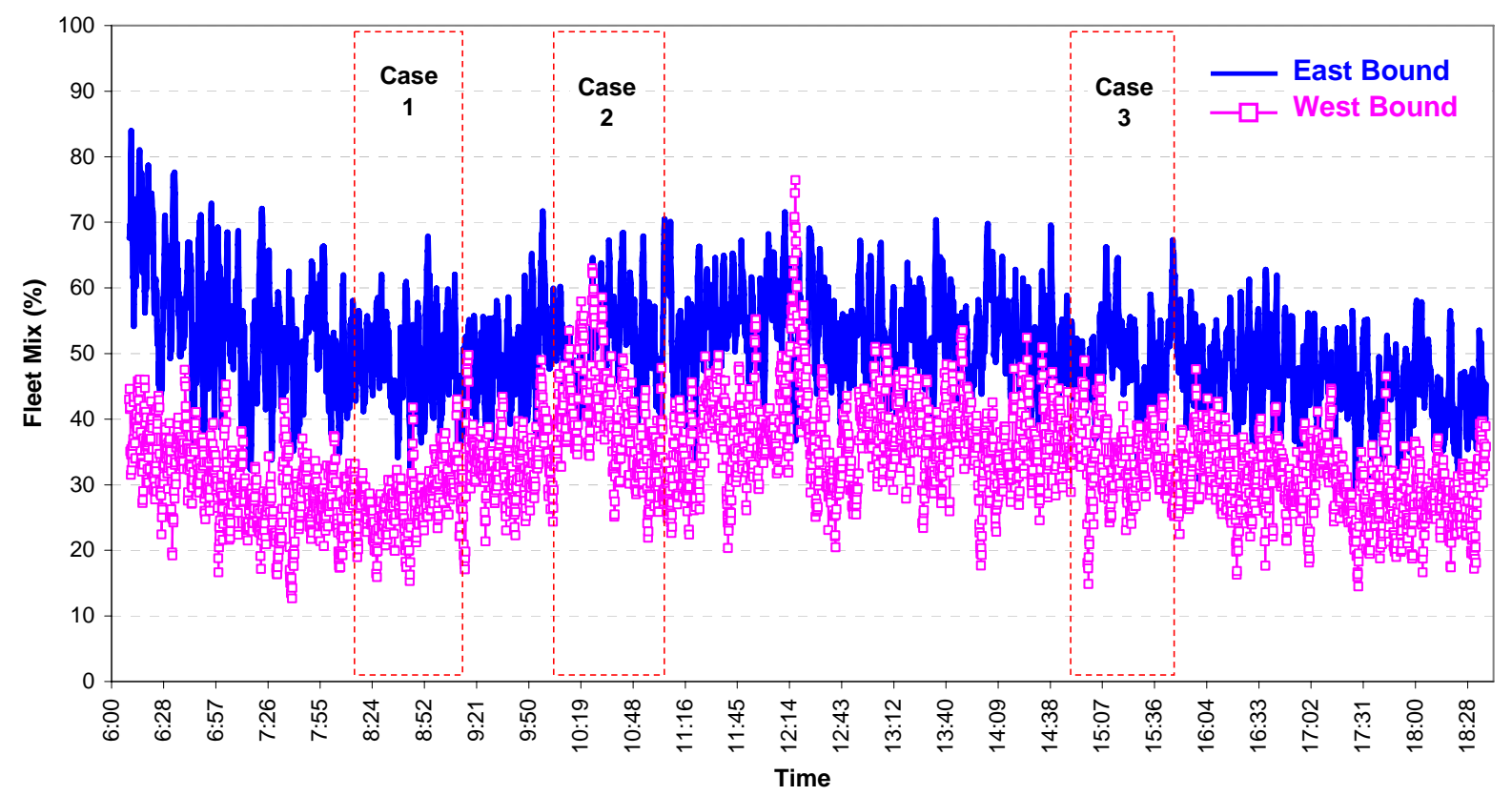

Figure 24. Average fleet mix as a function of time for both the east and west bounds of the Borman Expressway, 3/15/2005. Curve is smoothed using a moving average function of order 10.

\section{IMPLEMENTATION: THE TRAFFIC-AIR-QUALITY INDEX}

The TAQ Model provided a simple real-time tool to estimate fine particulate emissions using solely real-time traffic parameters collected along expressways. The proposed Traffic-Air-Quality index is an air quality level (a specific pollutant emission level $[\mathrm{g} / \mathrm{km}]$ ) above which local air quality and the pollutant concentrations around an expressway (or local roads in urban areas) would exceed the National Ambient Air Quality Standard (NAAQS) levels due to the increased emissions, and the air becomes hazardous to human health. Hence, similar to critical traffic parameters values above which congestion occurs, the Intelligent Transportation System (ITS) traffic management protocols, traffic-rerouting, and incident-counter-measure strategies can also be implemented once the local air quality reach the Traffic-Air-Quality index value and therefore maintain the air quality levels below the NAAQS requirements. This is especially useful in $\mathrm{PM}_{2.5}$ non-attainment counties. ITS traffic management protocols, and traffic diversion plans have not been introduced as a measure to control air quality levels in non-attainment areas (areas where air pollution levels exceed the NAAQS 
levels). This is in sharp contrast to the legislated standards used for other sources such as industrial sources, local households, and businesses. Figure 25 is a schematic diagram that shows the different contributors to the local air quality levels in an urbanindustrialized area and their control measures such as the industrial emission standards presented by the Clean Air Act of 1970 and its amendments ${ }^{[21]}$ and the EPA local-airquality index Clean Air Act of 1970 and its amendments ${ }^{[21]}$.

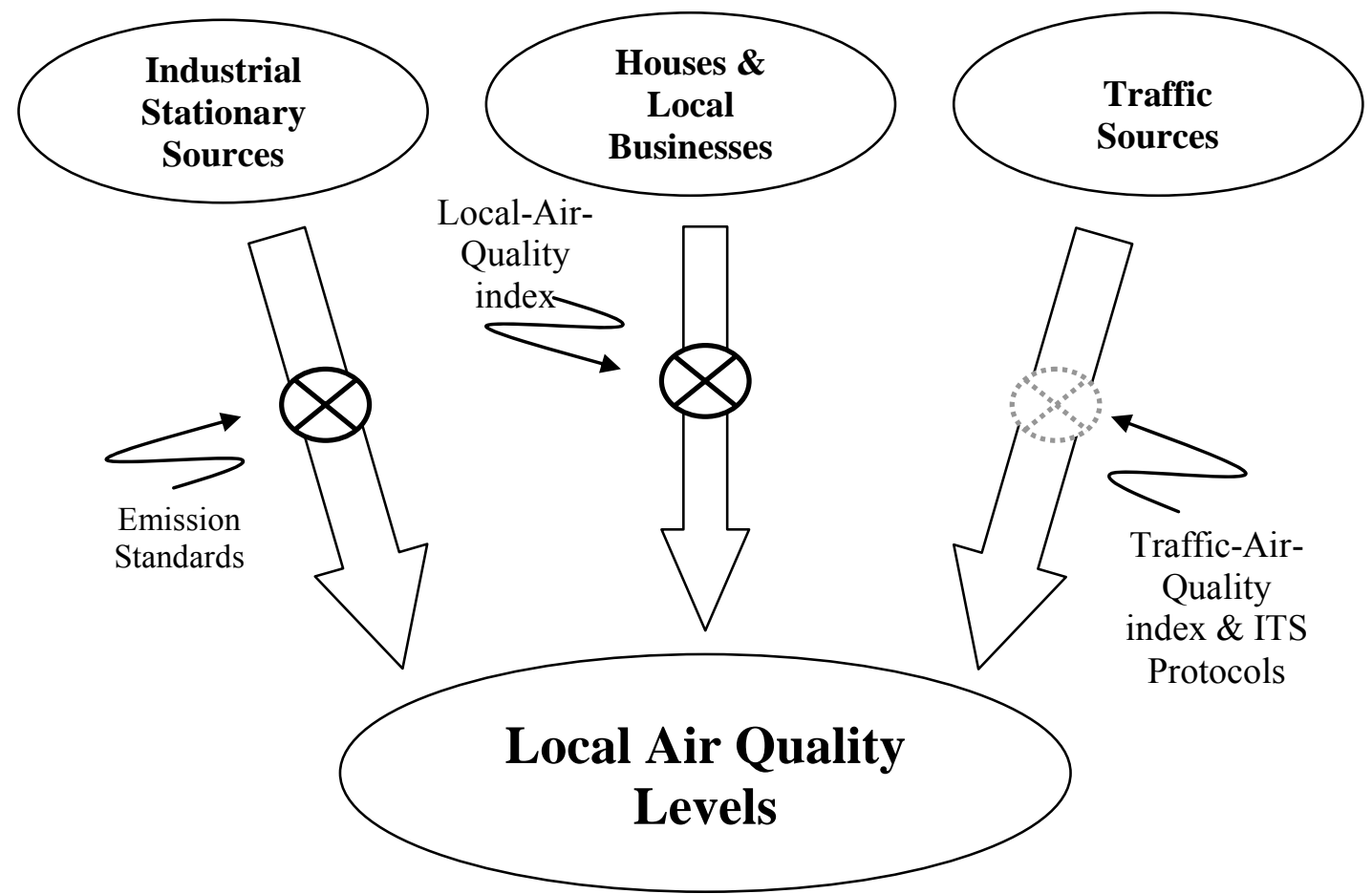

Figure 25. A schematic diagram of air pollution sources in urban areas and their control measures. 
Figure 26 shows a schematic diagram of a hypothetical expressway in a $\mathrm{PM}_{2.5}$ non-attainment county where the expressway is divided into segments where the fine particulate emissions are calculated using the TAQ Model based on the real-time collected traffic data. The emissions per road segment is compared to the TAQ-Index or the emission quota designated for the expressway and designated "Green"; i.e. emissions are below assigned quota, "Yellow"; i.e. emissions are at the assigned quota, and "Red", i.e. emissions are above the assigned quota and traffic measures need to taken in order to reduce the particulate emissions back to the "Yellow" or "Green" stages.

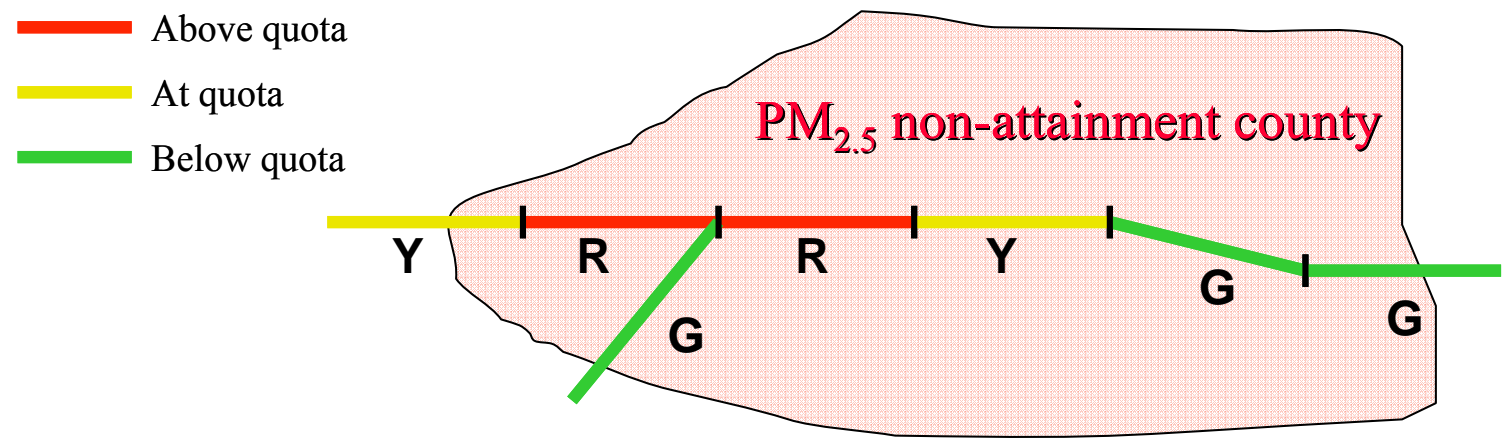

Figure 26. A schematic diagram showing an expressway's segments conditions from an air quality point of view in a $\mathrm{PM}_{2.5}$ non-attainment area. Above quota $=\mathbf{R}$, At quota $=\mathbf{Y}$, Below quota $=\mathbf{G}$.

\section{SUMMARY}

The Traffic-Air Quality Model (TAQ-Model) is a simple tool to estimate traffic fine particulate emissions on roadways in pollutant-mass per road-length and can be used for both real-time analysis and localized conformity analysis (non-attainment areas "hotspot" analysis) as defined by 40 CFR 93.123. This paper showed how local air quality levels should be a factor in traffic management in non-attainment areas. Similar to the industrial sources quotas measured in tons per year, it is proposed that road-segments are to be assigned emission quotas (or Traffic-Air Quality Indices) measured in pollutant mass emitted per road length (for example $[\mathrm{g} / \mathrm{km}]$ ) above which traffic-measures have to be taken to reduce the fine-particulates emissions on such road links. The TAQ-indices 
will differ from one area to another based on the level of contribution of the mobile sources to the local measured pollutant concentration compared to the contribution of the stationary sources in the area. The TAQ Model as well as traffic-rerouting measures along with the Intelligent Transportation System (ITS) protocols can be used to have a real-time control of the traffic conditions along expressways to maintain the fineparticulates emissions below the quota assigned per road link and consequently improving the over all local air quality in non-attainment areas. 


\section{REFERENCES}

1. Tsai, Jiun-Horng, Yih-Chyun Hsu, Hung-Cheng Weng, Wen-Yinn Lin, Fu-Tien Jeng, "Air pollutant emission factors from new and in-use motorcycles", Atmospheric Environment, vol. 34, 2000, pp. 4747-4754.

2. Durbin, Thomas D., Ryan D. Wilson, Joseph M. Norbeck, J. Wayne Miller, Tao Huai, Sam H. Rhee, "Estimates of the emission rates of ammonia from light-duty vehicles using standard chassis dynamometer test cycles", Atmospheric Environment, vol. 36, 2002, pp. 1475-1482.

3. Ubanwa, B. , A. Burnette, S. Kishan, S. G. Fritz, "Exhaust Particulate Matter Emission Factors and Deterioration Rate for In-Use Motor Vehicles", Journal of Engineering for Gas Turbines and Power, vol. 125, no. 2, April 2003, pp. 513-523.

4. Kristensson, Adam, et. al, "Real World Traffic Emission Factors of Gasses and Particles Measured in a Road Tunnel in Stockholm, Sweden", Atmospheric Environment, vol. 38, 2004, pp. 657-673.

5. Gramotnev, G. et. al, "Determination of Average Emission Factors for Vehicles on a Busy Road", Atmospheric Environment, vol. 37, 2003, pp. 465-474.

6. Ketzel, M., Wahlin, P., Berkowicz, R., "Particle and Trace Gas Emission Factors Under Urban Driving Conditions in Copenhagen Based on Street and Roof Level Observation", Atmospheric Environment, vol. 37, 2003, pp. 2735-2749.

7. Jamriska, M., Morawska, L., "A Model for Determination of Motor Vehicle Emission Factors From On-Road Measurements With a Focus on Sub-micrometer Particles", The Science of Total Environment, vol. 264, 2001, pp. 241-255.

8. Premo, Todd A., "Acceleration Effect on Vehicle Emission Measured Real-Time Using Fourier Transform Infrared Spectroscopy". M.S. Thesis, Purdue University, May 1998.

9. Chan, T.L., et. al, "On-Road Remote Sensing of Petrol Vehicle Emissions Measurements and Emission Factors Estimation in Hong Kong", Atmospheric Environment, vol. 38, 2004, pp. 2055-2066.

10. Veurman, J., N.L.J. Gense, I.R. Wilmink, and H.I. Baarbe, "Emissions at Different Conditions of Traffic Flow", Proceeding of the seventh Inernational Conference on Urban Transport and the Environment, 2002, pp. 571-580.

11. Bellasio, Roberto, "Modeling Traffic Air Pollution in Road Tunnels", Atmospheric Environment, vol. 31, no. 10, 1997, pp. 1539-1551. 
12. Eskridge, Robert E., Hunt, J. C. R., "Highway Modeling, Part 1: Prediction of Velocity Turbulence Fields in the Wake of Vehicles", Journal of Applied Meteorology, vol. 18, no. 4, April 1979, pp. 387-400.

13. Hider, Z. E., S. Hibberd, and C. J. Baker, "Modeling Particulate Dispersion in the Wake of a Vehicle", Journal of Wind Engineering and Industrial Aerodynamics, vol. 67\&68, 1997, pp. 733-744.

14. Eskridge, Robert E., Rao, S. Trivikrama, "Measurements and Prediction of TrafficInduced Turbulence and Velocity Fields Near Roadways", Journal of Climate and Applied Meteorology, vol. 22, no. 8, Aug 1983, pp. 1431-1443.

15. Rao, K.S., Gunter, R.L.; White, J.R.; Hosker, R.P., "Turbulence and dispersion modeling near highways", Atmospheric Environment, vol. 36, no. 27, September 2002, pp. 4337-4346.

16. Baker, C.J., Hargreaves, D.M., "Wind Tunnel Evaluation of a Vehicle Pollution Dispersion Model", Journal of Wind Engineering and Industrial Aerodynamics, vol. 89, 2001, pp. 187-200.

17. "ITS Strategies for Minimization of Fine Particulates", SPR-2926, Joint Transportation Research Program (JTRP), File No. 9-10-79, Project No. C-3667BBBB, December 2005. Authors: Ahmed Soliman, Robert B. Jacko, Barry K. Partridge.

18. Soliman, Ahmed S. M., Jacko, Robert B., and Palmer, George M., "Development of an Empirical Model to Estimate Real-World Fine Particulate Matter Emission Factors: The Traffic-Air-Quality Model". The Journal of Air and Waste Management Association, volume 56, 1540-1549, November 2006.

19. Garber, Nicholas J., and Lester A. Hoel, Traffic and Highway Engineering, Third Edition (Brooks/Cole Inc., California, 2002).

20. Coifman, B. "Estimating Travel Times and Vehicle Trajectories on Freeways Using Dual Loop Detectors", Transportation Research: Part A, 2002, vol. 36, no 4, 2002, pp. 351-364.

21. Kenneth Wark, Cecil F. Warner, and Wayne T. Davis, Air Pollution, its Origin and Control, $3^{\text {rd }}$ edition, pp. 70, 189 (Addison-Wesley, California, 1998). 